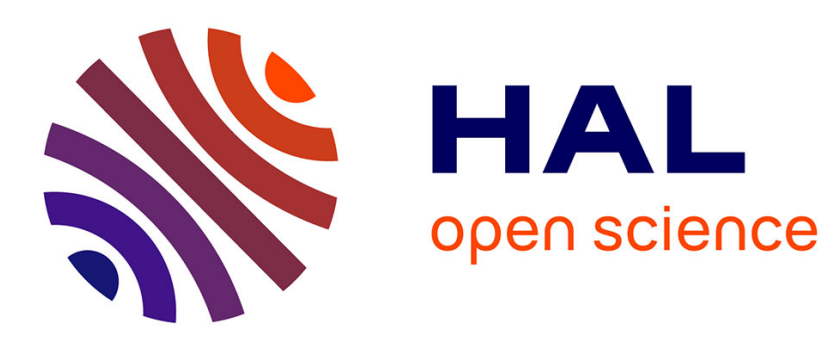

\title{
Heat transfer from a hot moving cylinder impinged by a planar subcooled water jet
}

Michel Gradeck, Arsene Kouachi, Jean-Luc Borean, Pascal Gardin, Michel

Lebouché

\section{- To cite this version:}

Michel Gradeck, Arsene Kouachi, Jean-Luc Borean, Pascal Gardin, Michel Lebouché. Heat transfer from a hot moving cylinder impinged by a planar subcooled water jet. International Journal of Heat and Mass Transfer, 2011, 54 (25-26), pp.5527-5539. 10.1016/j.ijheatmasstransfer.2011.07.038 . hal01579238

\section{HAL Id: hal-01579238 \\ https://hal.univ-lorraine.fr/hal-01579238}

Submitted on 30 Aug 2017

HAL is a multi-disciplinary open access archive for the deposit and dissemination of scientific research documents, whether they are published or not. The documents may come from teaching and research institutions in France or abroad, or from public or private research centers.
L'archive ouverte pluridisciplinaire HAL, est destinée au dépôt et à la diffusion de documents scientifiques de niveau recherche, publiés ou non, émanant des établissements d'enseignement et de recherche français ou étrangers, des laboratoires publics ou privés. 


\title{
HEAT TRANSFER FROM A HOT MOVING CYLINDER IMPINGED BY A PLANAR SUBCOOLED WATER JET
}

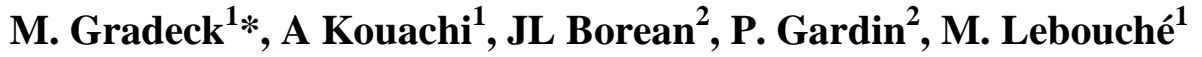 \\ ${ }^{1}$ LEMTA, Nancy University-CNRS, Vandoeuvre lès Nancy, France \\ ${ }^{2}$ AM Research, Maizières lès Metz, France
}

\begin{abstract}
A hot moving (rotating) cylinder was heated up to $500-600^{\circ} \mathrm{C}$ and then was cooled by a planar water jet impinging on a line parallel to the symmetry axis. The time dependent wall temperature was measured using embedded thermocouples and the corresponding wall heat fluxes were estimated through an inverse conduction method. In a recent paper, we showed that cooling rates depend on the subcooled temperature of the jet, the velocity of the jet and the surface-to-jet velocity ratio. Since the initial temperature of the cylinder was higher than the Leidenfrost temperature, we observed all the boiling regimes from film boiling to nucleate boiling. The objectives of this paper are firstly to describe the current conditions which exist in the Run Out Table in hot rolling mills, secondly to review the main experimental studies dedicated to jet cooling which have led to modelling heat transfer in boiling conditions and finally to propose new correlations taking into account the velocity of the wall.
\end{abstract}

Key words: Heat transfer, Inverse solution, Heat conduction, Impinging jet, Transient boiling

$\begin{array}{ll}\alpha & \text { Nomenclature } \\ d & \text { heat transfer coefficient }\left[\mathrm{W} \cdot \mathrm{m}^{-2} \cdot \mathrm{K}^{-1}\right] \\ q, & \text { heat flux }\left[\mathrm{W} \cdot \mathrm{m}^{-2}\right] \\ \operatorname{Re} & \text { Reynolds Number } \\ \operatorname{Pr} & \text { Prandtl number }\end{array}$

\footnotetext{
${ }^{1}$ Corresponding author : michel.gradeck@ensem.inpl-nancy.fr
} 
$\Delta T_{\text {sub }} \quad$ subcooled temperature $[\mathrm{K}]$

$\Delta T_{\text {sat }} \quad$ superheat temperature $[\mathrm{K}]$

$\mathrm{T}$ temperature $\left[{ }^{\circ} \mathrm{C}\right]$

$V_{J} \quad$ jet velocity at the impingement $\left[\mathrm{m} . \mathrm{s}^{-1}\right]$

$V_{n} \quad$ jet velocity at the exit of the nozzle $\left[\mathrm{m}_{\mathrm{s}} \mathrm{s}^{-1}\right]$

$V_{S} \quad$ wall velocity $\left[\mathrm{m} . \mathrm{s}^{-1}\right]$

$\lambda \quad$ conductivity $\left[\mathrm{W} \cdot \mathrm{m}^{-1} \cdot \mathrm{K}^{-1}\right.$ ]

$\mu \quad$ dynamic viscosity [Pa.s]

$\sigma \quad$ surface tension $\left[\mathrm{N} . \mathrm{m}^{-1}\right]$

$r^{*} \quad$ dimensionless velocity, $\frac{V_{S}}{V_{J}}$

$x \quad$ distance from the jet axis (m)

$x^{*} \quad$ dimensionless distance, $\frac{x}{d}$

Subscripts

FB film boiling

MFB minimum of film boiling

TB transition boiling

NB nucleate boiling

TC transient conduction

CHF critical heat flux

L liquid

V vapour 


\section{Introduction}

In the steel industry, cooling on the Run Out Table (ROT) after hot rolling is one of the most difficult process steps in the hot mill strip. The decrease in the temperature needs to be perfectly controlled because the mechanical properties of steel alloys are conditioned by the cooling rate ensured by these jets [1-4]. Generally, top cooling is carried out using a number of subcooled water jets which impinge perpendicularly on the hot steel surface while bottom cooling is done using sprays. The water jets are organized in a set called a header where two jets rows are either aligned or staggered. Complex flows are thus obtained, as a result of the interaction between the jets and the moving surface. In-depth knowledge on the heat transfer associated to that flow is therefore essential including knowledge of the interaction between the jet and the moving surface, the interaction between the jets and the interaction between the ramps.

Rates of cooling will vary between $15 \mathrm{~K} / \mathrm{s}$ and $1000 \mathrm{~K} / \mathrm{s}$ depending on the required steel mechanical property. Although cooling technologies based on the so-called laminar water jets have been widely studied in the past, knowledge of these technologies remains incomplete which means it is difficult to attain optimum production. Obviously the kinetics of cooling depends on the various boiling regimes met during transient cooling (i.e. the metal slab is reheated before rolling, the temperature of the strip after rolling is about $900^{\circ} \mathrm{C}$ and after cooling, the temperature should be between $200^{\circ} \mathrm{C}$ and $500^{\circ} \mathrm{C}$, depending on steel grade). At the very beginning of the cooling phase, the temperature of the steel strip is above the Leidenfrost temperature so film boiling , transition boiling, critical heat flux (CHF) and nucleate boiling all occur. Controlling the cooling rate and the homogeneity thereof thus remains a major challenge for manufacturers aiming to produce steels with desired and homogeneous mechanical properties. 


\section{1 description of the flow on the Run Out Table (ROT)}

As previously described, the heat transfer can not be homogeneous when using water jets in the cooling system because of flow topology and because the water film depth above the hot surface is not constant. This depends on the distance from the impact zone of the jet but also on the ratio between velocity of the jet and the velocity of the moving surface. In a recent paper, Gradeck et al. [5] carried out experimental and numerical studies of the flow structure of a single water jet impinging on a moving surface. This work provided a valuable correlation to predict the position of the hydraulic water jump for operating conditions similar to those in ROT cooling systems. In a more recent paper, the flow pattern of multiple water jet impinging on a moving surface was numerically studied by Cho et al [6] using the CFD Fluent package. Their computations clearly showed how flow patterns are dependant on the running conditions (flow rates, velocity of the surface). At low flow rates, hydraulic jumps were observed while with increasing values of the flow rates, the hydraulic jumps disappeared and a pool was observed. Moreover, a fountain effect was found to occur at times between two adjacent jets with consequent improvement of the cooling flux. Monde et al. [7] gave an illustration of the interactions of neighbouring jets and the expected increase of the heat flux in this area. However in more recent study, Franco [8] did not find a fountain effect to occur whether the alignment of the jets was staggered or aligned. The large distance between jets (around 100mm) in Franco's [8] experiments is the probable explanation.

\subsection{Heat transfer associated with single impinging jet}

Most studies of heat transfer associated with impinging jets have been carried out using a static surface which means that the dynamic conditions as mentioned above may have been far from industrial conditions [9-15]. However, most correlations from these studies are used as command and control for the ROT even though the influence of surface velocity was not addressed in these 
studies. Depending on the strip temperature, four different water cooling regimes may be encountered: (i) for high temperatures, only film boiling ; (ii) transition boiling if the surface temperature of the strip is lower than the Leidenfrost temperature; (iii) nucleate boiling regime if the surface temperature is lower than the CHF temperature and finally (iv) forced convection (Fig. 1a). A particular shape of boiling curve may be observed in the transition regime in the case of an impinging jet on a hot plate (Fig. 1b). After CHF, a first minimum of flux was observed after which the heat flux increased again and reached a high value. This "shoulder of flux" was found to falls down abruptly to film boiling regime for very high superheats. Miyasaka et al [15], Ishigai et al. [9], Ochi [10] and Hall [3], Robidou et al [13] and Gradeck et al [16] have reported the existence of a "shoulder of flux" beneath the jet (transition boiling regime) in the case of static surface. But Gradeck et al [16] showed that heat transfer is radically modified when the impingement surface is moving. They found that the "shoulder of flux" beneath the jet axis collapsed and that the local boiling curves had the same shape upstream, downstream and beneath the centreline of the jet.

\subsection{ROT heat transfer model}

Given that cooling rates (i.e. heat transfer at the wall) are affected by the temperature of the strip, dedicated correlation needs be applied to the off-line or on-line models used in ROT in order to correctly predict the coiling temperature of the strip. Since the heat transfer model used in the ROT control is usually simple, consisting of a simple polynomial relationship [17-19], improvements should be done to consider four heat transfer regimes (Fig. 1) and two significant temperatures (Leidenfrost and CHF temperatures). In the following sub-sections, we give an overview of the correlations (or models) available for impinging jets in these four boiling regimes. 


\subsubsection{Film boiling}

Stagnation zone

Zumbrunnen et al. [20-21] and Filipovic [22] obtained models for the film boiling regime by solving the boundary layer equations but as some strong assumptions have been assumed to simplify the Navier-Stokes equations and obtain an analytical solution, these models can be very far from the current application. For example neglecting waviness on the vapour-liquid interface as well as Kelvin-Helmotz instabilities lead to delay the minimum of film boiling (in comparison with measurements).

Liu et al. [23-24] derived an analytical expression of the heat flux for the film boiling regime in the stagnation zone $(\mathrm{C}=1.414)$. To fit the experiments, the constant $\mathrm{C}$ of the original expression was slightly modified to take into account the interfacial waviness of the vapor layer $(\mathrm{C}=2)$.

$$
q^{\prime \prime}{ }_{F B}=C \operatorname{Re}_{J}^{0,5} \operatorname{Pr}_{J}^{0,166}\left(\lambda_{L} \lambda_{v} \Delta T_{s u b} \Delta T_{s a t}\right)^{0,5} / d
$$

where the thermal properties of water were evaluated at the film temperature of water and vapor properties evaluated at the film temperature of vapour.

Ochi et al. [10] proposed the following correlation

$$
q_{F B}^{\prime \prime}=3.18 \times 10^{5}\left(1+0.383 \Delta T_{\text {sub }}\right)\left(V_{J} / d\right)^{0.828}
$$

A similar expression was found by Ishigai et al. [9] for a planar jet:

$$
q_{F B}^{\prime \prime}=5.4 \times 10^{4}\left(1+0.527 \Delta T_{\text {sub }}\right) V_{J}^{0.607}
$$

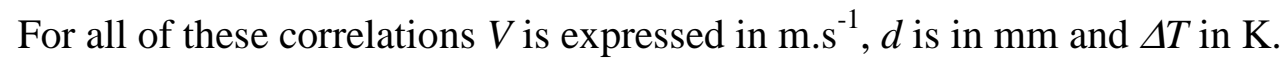

Robidou [25] used an innovative experimental device to measure boiling curves under steady state conditions and proposed the following correlation at the stagnation zone:

$$
q_{F B}^{\prime \prime}=5.38 \times 10^{4}\left(5.5+\Delta T_{\text {sub }}\right) V_{J}^{0.6}
$$


Few models exist in the parallel flow zone $\left(x^{*}>2\right)$. Filipovic [22] developed a model for this regime based on the boundary layers equations and measurements achieved on a parallel jet. Hatta et al. [26] proposed the following correlation fitting the experimental data of Kokado et al. [27] obtained for a transient cooling.

$\alpha=200\left(2420-21.7 T_{L}\right) \Delta T_{s a t}^{-0.8}$

This correlation underestimated the heat transfer coefficient in comparison with the values measured by Robidou [25] at the Minimum of Film Boiling (MFB).

\subsubsection{Temperature for the minimum film boiling (MFB)}

Several results can be found concerning the temperature for the MFB (i.e. $T_{M F B}$ ) in the stagnation zone. Liu [24] gave an expression for the temperature of minimum film boiling, $T_{M F B}$.

$$
\Delta T_{M F B}=14 \Delta T_{s u b} \operatorname{Pr}_{J}^{0,33}\left(\lambda_{L} / \lambda_{V}\right)\left(\mu_{L} / \mu_{V}\right)
$$

And the associated heat flux:

$$
q_{F B, M F B}^{\prime \prime}=0.5 \Delta T_{M F B} \lambda_{V} \operatorname{Re}_{J}^{0,5} \operatorname{Pr}_{J}^{0,166}\left(\mu_{L} / \mu_{V}\right)^{0,5} / d
$$

where the thermal properties of water were evaluated at the film temperature of water and vapor properties evaluated at the film temperature of vapor. Following Liu [24], $T_{M F B}$ depends only on water properties and subcooling and hydrodynamics does not have any effect (see expression 6), Kokado et al. [27]:

$T_{M F B}=a-b T_{L}$

with $\mathrm{a}=1100^{\circ} \mathrm{C}, \mathrm{b}=8.5$ for Kokado's experiment. 
The previous relationship must be used according to the critical temperature, $T_{c}$ (which was $68^{\circ} \mathrm{C}$ in the case of Kokado's experiments): (i) If $T_{L}<T_{c}$, a wetting regime occurs; (ii) if $T_{L}>T_{c}$ and $T_{W}$ $<T_{M F B}$, a partial wetting regime occurs; (iii) if $T_{L}>T_{c}$ and $T_{W}>T_{M F B}$, film boiling can occur. Following on from these results, under the jet and for water temperature below $40^{\circ} \mathrm{C}$, the wall is always in a wetted regime.

Hatta and Osakabe [28] used the water temperature whereas Robidou [25] used the subcooling.

$$
T_{M F B}=326+17.6 \Delta T_{s u b}^{0.8}
$$

A change of $T_{M F B}$ according to the hydrodynamics of the jet-wall interaction needs to be taken into account in this expression.

In a recent paper, Karwa et al. [29] have also developed a simplified two-phase analytical model for predicting of the $T_{M F B}$ in the case of a planar or a circular liquid jet impinging on a flat hot wall. They provided the following equation:

$$
\begin{array}{ll}
\Delta T_{M F B}=0.7 \Delta T_{\text {sub }} \operatorname{Pr}_{L}^{0,5} \operatorname{Re}_{L}^{0,5}\left(\lambda_{L} / \lambda_{V}\right)\left(\delta_{V} / w\right) \quad \text { for a planar jet } \\
\Delta T_{M F B}=1.6 \Delta T_{\text {sub }} \operatorname{Pr}_{L}^{0,5}\left(\lambda_{L} / \lambda_{V}\right)\left(\mu_{L} / \mu_{V}\right)^{0,5} \quad \text { for a circular jet }
\end{array}
$$

where the properties of vapour are taken at the bulk temperature, $w$ is the width of the jet just before impingement and $\delta_{V}$, the vapour thickness.

\subsubsection{Transition boiling}

Transition boiling is an important regime because it is at the origin of control issues. When the strip temperature decreases, the extracted heat flux increases and the temperature discrepancies are amplified because of high discrepancies on local heat flux. A definition of the transition boiling was provided by Berenson [30], Kalinin et al. [31] and Pan et al. [32] namely a 
combination of unstable film boiling and unstable nucleate boiling alternately existing at any given location on a heating surface. The extracted heat flux in the transition boiling was provided by (Kalinin et al. [31]):

$$
q_{T B}^{\prime \prime}=\frac{q^{\prime \prime} t_{T C}+q_{N B}^{\prime \prime} t_{N B}+q_{F B}^{\prime \prime} t_{F B}}{t_{T C}+t_{N B}+t_{F B}}
$$

With $T B$, Transition Boiling; $T C$ : Transient Conduction; $N B$, Saturated Nucleate Boiling; $F B$, Film Boiling; $\mathrm{t}$ fraction of time, contact time of each regime.

For Nagai and Nishio [33], Ohtake and Koizumi [34], transition boiling is a stationary boiling regime and the heat flux is expressed as:

$$
q^{\prime \prime}{ }_{T B}=\Gamma q^{\prime \prime}{ }_{N B}+(1-\Gamma) q_{F B}^{\prime \prime}
$$

In fact both approaches lead to the last equation with the weighting parameter having a different meaning when transient conduction is assumed as negligible. In the case of time-dependant models, the weighting $\Gamma$ is based on contact time whereas it is based on the liquid-solid contact fraction area in stationary models. These approaches are very interesting because expressions can be adapted to the case of the ROT using experiments. The current parameters used are obtained for nuclear reactor applications by using droplets, pool boiling experiments, vertical tubes, saturated fluid, temperatures below $300^{\circ} \mathrm{C}$, with surfaces (copper, sapphire, etc) whose thermal properties are very different from those of steel. These cannot be used for the Run-Out Table without prior adaptations. Moreover the moving effect of the surface is not taken into account at all although Gradeck et al. [16] found this significantly modifies the boiling curve and transition boiling regime. 


\subsubsection{Critical heat flux, CHF}

Monde [35] and his team (Mitsutake and Monde [36], Hammad et al. [37]...) have carried out a lot of experiments in the field of impinging jets and they have provided a correlation to estimate the CHF:

$$
\left\{\begin{array}{l}
\frac{q^{\prime \prime}{ }_{C H F}}{q_{0}}=\frac{1+\sqrt{1+4 C J a}}{2} \\
J a=\frac{\rho_{L}}{\rho_{V}} \frac{C p \Delta T_{s u b}}{h_{L V}} \\
q_{0}=0.221\left(\frac{\rho_{L}}{\rho_{V}}\right)^{0.645}\left(\frac{2 \sigma}{\rho_{L} V_{J}^{2}(D-d)}\right)^{0.343}(1+D / d)^{-0.364} \\
C=\frac{0.95(d / D)^{2}(1+D / d)^{0.364}}{\left(\rho_{L} / \rho_{V}\right)^{0.43}\left(2 \sigma / \rho_{L} V_{J}^{2}(D-d)\right)^{0.343}}
\end{array}\right.
$$

where D was the size of the heater and thermal properties were evaluated at the saturated temperature. This correlation is applicable for stationary applications, static surface and to a $\frac{\rho_{L}}{\rho_{V}}$ of $5.3 \sim 1603$, the inverse Weber number (second term in brackets) of $2.10^{-7}$ to $10^{-3}$ and $\mathrm{D} / \mathrm{d}$ of 5 $\sim 30$.

Miyasaka et al. [15] found the following relationship to estimate CHF for a planar jet impinging a static plate

$$
q^{\prime \prime}{ }_{C H F}=0,16 h_{l v} \rho_{v}\left(1+0,86 V_{n}^{0,38}\right)\left(1+0,112\left(\frac{\rho_{l}}{\rho_{v}}\right)^{0,8}\left(\frac{c_{p_{l}} \Delta T_{s u b}}{h_{l v}}\right)^{1,13}\right)\left(\frac{\sigma g\left(\rho_{l}-\rho_{v}\right)}{\rho_{v}{ }^{2}}\right)^{0,25}
$$

Although the hydrodynamic parameters used are not too far from the requirements of the ROT, several points prevent the extension of these correlations to the ROT including:

$\rightarrow$ The surface is fixed

$\rightarrow$ Experiments are dependent on the size of heater, which is a parameter of the correlations. 


\subsubsection{Nucleate boiling}

Wolf [12], Wolf et al. [38] proposed correlation (9) for nucleate boiling.

$$
q^{\prime \prime}{ }_{N B}=63.7 \Delta T_{\text {sat }}^{2.95}
$$

Following Wolf's finding [12], the previous correlation can also be applied in a parallel flow configuration.

$$
q^{\prime \prime}{ }_{N B}=a \Delta T_{s a t}{ }^{b}
$$

This correlation means that heat transfer does not depend on hydrodynamics in this regime.

Filipovic et al. [39-40] proposed the following correlation (for a static surface) taking into account the velocity of the jet, subcooling, the diameter of the nozzle and superheat. However this correlation also overestimates the heat flux in the case of nucleate boiling for moving system.

$q^{\prime \prime}{ }_{N B}=C\left(\Delta T_{\text {sub }}\right) V_{j}^{0.5} d^{-0.608} \Delta T_{\text {sat }}^{0.14}$

where $\mathrm{C}\left(\Delta T_{\text {sub }}=80^{\circ} \mathrm{C}\right)=1.3 \cdot 10^{7}$ and $\mathrm{C}\left(\Delta T_{\text {sub }}=65^{\circ} \mathrm{C}\right)=0.81 \cdot 10^{7} ; V_{j}$ in $\mathrm{m} / \mathrm{s}, d$ in $\mathrm{mm}$

\subsection{Concluding remarks on our literature review}

The real process is extremely complicated because of the multiple interactions involved namely the interaction of the jet with the band, of a jet with another jet or of a header with another header. This means it is impossible to cover all these situations at the same time in the context of a simple laboratory experiment. Hence previous studies have always been carried out using simple configurations such as multiple jet impinging a cold plate, a single jet impinging a moving cold plate or a single jet impinging one plate whose temperature was higher than the Leidenfrost temperature. Previous theoretical approaches also used a simple situation as their 
starting point, for example an axisymmetric jet impinging a static cold surface or planar jet impinging a moving plate (cold or hot). For our study, we opted to experiment with a new situation, namely a planar jet impinging a hot moving surface (i.e. a rotating cylinder). The table 1 gives an overview of the running conditions for the different experimental works which have been previously mentioned.

\section{Experimental set-up and data reduction}

The experimental device was designed to allow local and instantaneous determination of the heat transfer coefficient between a water jet impinging a moving surface. This estimation was quite accurate because we used temperature measurements of the wall surface and calculating the cooling heat flux by means of an inverse conduction method [41]. This device is illustrated in Fig. 2.

\subsection{Experimental set-up}

The cooling of the steel strip in the ROT can be approximated using a rotating hot cylinder which respects the main process parameters of the cooling to some extent namely the speed of the moving surface, its temperature and the jet characteristics (flow rate and water temperature). The results obtained in this study of heat transfer beneath the jet and close to the impact zone (in these zones, the effect of the curvature is negligible) can used for ROT characterisation. However, this device cannot be used to simulate the effect of the accumulation of water because in the real process a certain amount of water can be transported by the steel strip. Of course, water accumulation is also a parameter that should be considered in future works because heat transfer may be different for a free jet or a submerged jet. 
The set-up is schematically outlined in Fig. 2a and photos show details of the device in Fig. 2 b. The boiling vessel contained the jet (5) and the hot rotating cylinder (7). The external diameter of the outer cylinder (which is cooled by the jet) was equal to $175 \mathrm{~mm}$ and its internal diameter equals $100 \mathrm{~mm}$. The length of this cylinder was $200 \mathrm{~mm}$. Heating was provided by three electrical wires which were wound on an inner cylinder $\left(\varnothing_{\text {out }}=100 \mathrm{~mm}, \varnothing_{\text {in }}=85 \mathrm{~mm}\right)$ which itself was adjusted with the outer cylinder. Heating with a constant heat flux $(P)$ was thus applied on the internal radius until thermal equilibrium was reached (uniform wall temperature required for the test of about $600^{\circ} \mathrm{C}$ on the external radius). Each resistance used can dissipate $2000 \mathrm{~W}$ (10). The wall temperature was almost uniform because heat losses (radiation and convection) were almost uniform (i.e. the cylinder rotates during the heating phase). Two cooled stainless steel flasks (6) were set out on both sides to prevent the revolving contacts, ball bearings and sealing rings from excessively high temperatures. This was also used to center the cylinder and thus avoid the unbalances. The system was allowed to dilate without generating additional constraints inside the set-up. Axial losses (i.e. axial conduction) are impossible to avoid but as the cylinder was long enough and thermocouples placed in the middle of it, we only considered a $2 \mathrm{D}$ conduction problem to solve the inverse problem related to the estimation of heat flux [41]. 24 thermocouples ( $\mathrm{N}$ type) were inserted near the external surface in grooves and a coating was deposited. The electrical output was provided to resistances by means of revolving contacts (8a). The test fluid (water) was first heated at a subcooled temperature in a vessel (1) and circulated in a primary circuit. The flow rate was adjusted using a pump (2) and controlled using an electromagnetic flowmeter (3). When all the initial parameters were adjusted, the electromagnetic sluice gate (4) was opened and the cooling of the cylinder could start. The jet had an outlet cross sectional area of $180 \times 4 \mathrm{~mm}^{2}$ and the water jet outlet was located at a distance $H$ from the hot cylinder and impinged the higher line of the cylinder. This distance could be adjusted. The pre-amplified signals of the thermocouples as well as their angular positions (i.e. a 
position sensor was available on the driveshaft) were then also transmitted to a computer (11) via revolving contacts $(8 \mathrm{~b})$ to be recorded. This meant we could construct the time evolution of temperature at each point on the surface of the cylinder. More details on this device can be found in [42]

\subsection{Data reduction}

When the cylinder reached the equilibrium temperature, the heating was stopped and the jet cooling began at $\mathrm{t}=0$ (opening of the sluicegate). During cooling, the heat flux was estimated through inversion of the temperature measurements using an Inverse Heat Conduction Model (IHCM); see Volle et al. [41]. This model was based on an analytical solution of the 2D transient heat equation. As axial conduction was neglected, we therefore worked with a $2 \mathrm{D}$ problem. The heat equation can be solved using a cylindrical reference with knowledge of the initial temperature field (i.e. an equilibrium temperature field obtained with a constant heat flux $\mathrm{P}$ at an internal radius with losses due to convection and radiation at the external surface and conduction at each end of cylinder). The use of spatial integral transform, see Maillet et al. [43], namely the Fourier transform (noted $\sim$ ), led us to obtain a linear relation (in the Fourier space) between the $\mathrm{k}^{\text {th }}$ harmonic of inside temperature ${ }^{2}$ and the $\mathrm{k}^{\text {th }}$ harmonic of heat flux lost on the cooled wall :

$$
\tilde{T}_{k}=\tilde{X}_{k} \tilde{q}_{k}
$$

with $\tilde{X}_{k}$, the sensitivity matrix linking variations of temperature responses to variations of wall heat flux input. Once $\tilde{T}_{k}$ was estimated through experimental measurements, $\tilde{q}_{k}$ could be calculated thanks to an inversion of the previous equation. Because of the standard noise

\footnotetext{
${ }^{2}$ the thermocouples were inserted at $500 \mu \mathrm{m}$ depth.
} 
deviation of experimental temperatures, an ordinary least square operator was used to obtain the most accurate estimation of the cooling heat flux in Fourier domain:

$$
\tilde{q}_{k}=\left(\tilde{X}_{k}^{T} \tilde{X}_{k}\right)^{-1} \tilde{X}_{k}^{T} \tilde{T}_{k}
$$

A Fourier inversion of the previous estimated signal led to the cooling flux identification as a function of time. Obviously the inverse problem is an ill-posed problem and it was thus necessary to use some regularization techniques. In our study, the probes were located close to the wall $(500 \mu \mathrm{m}$ depth) and we used a Beck future time regularization method to obtain a better estimation. The accuracy of the method was estimated using noisy data (i.e. temperature) which was obtained either using the analytical solution of the heat equation or numerical simulations. Any errors would depend on the choice of hyperparameters or regularization parameters (number of future times, number of harmonics) and of course on the noise level [44-45].

As we could know the position of the thermocouple as a function of time, it was then possible to link the time evolution of the temperature at a given point to the time-evolution of heat flux at the same point and thus to build the boiling curve corresponding to a curvilinear abscissa $x *$ (Fig. 3). An example of the data obtained (local boiling curves) is given in the Fig. 4. Thus we were able to identify the different heat transfer regimes namely forced convection, onset of nucleate boiling, nucleate boiling (Fig. 4b), critical heat flux (Fig. 4c), first minimum of film boiling and shoulder of flux (Fig. 4a).

\section{Heat transfer analysis and correlations}

\subsection{Heat transfer analysis}


As described in a previous paper [16], heat transfer does not evolve in the same way as in a static case and its value is clearly modified when the impingement surface is moving. As a consequence, the maximum of CHF is lower than in the static case [25]. But the most obvious effect was a kind of auto-similarity of the local boiling curves throughout the cooling zone. In fact, defining a local boiling curve at $x^{*}$ for a moving surface integrates all the boiling phenomena over the surface throughout the cooling zone upstream. Bubbles or vapour spot moved with the surface (for nucleate boiling and transition boiling regimes) and in the film boiling regime, the stability of the vapour layer is clearly hard to achieve which is why a kind of "shoulder of flux" was observed. For a static surface, the shoulder of flux was observed at the impingement of the jet $\left(x^{*}=0\right)$ but collapsed in the flow zone because the jet was spreading over a stable vapour film. Nevertheless, in a recent published paper [16], we especially shown a collapse of the "shoulder of flux" beneath the jet axis and a displacement of the maximum of heat transfer downstream. Another point is that the local boiling curves have slightly the same shape upstream, downstream and beneath the point of maximum heat transfer (i.e.maximum heat transfer was not always at the centreline of the jet; see Gradeck et al. [16]). The shape of the boiling curve looked rather like those beneath the impingement (Fig. 5). Seiler-Marie et al [46] have modelled the transition, from transition boiling to the shoulder of flux and this is based on the assumption of the existence of periodic bubble oscillations controlled by Rayleigh-Taylor instabilities namely that vapour spots would be fragmented by the jet hydrodynamic forces. In fact, for moving surfaces, rewetting the wall and thus stability of the vapour spots or film should be also controlled by Kelvin-Helmholtz instabilities.

Another point to be recalled is related to the position of the cooling zone (i.e. the zone corresponding to a temperature decrease): at the beginning of cooling, the cooling zone begins mainly beneath the jet and develops only downstream [16]. As a consequence, the maximum of 
heat transfer was not located beneath the jet and it moves during the cooling. An asymmetry of the heat transfer was also observed upstream and downstream from the maximum of heat transfer (Fig. 4). This was a consequence of the jet-wall interaction, especially when a counter current appeared (upstream) and induced rapid evolution of the velocity flow field.

The data bank obtained by Kouachi [42] was analyzed and heat transfer correlations for nucleate boiling and maximum heat transfer were proposed taking into account the main hydrodynamic parameters, the fluid properties, the fluid subcooling and also the dissymmetry of the heat transfer between upstream flow and downstream flow. Further experiments would be required to study other regimes like transition boiling or film boiling.

\subsection{Heat transfer associated with moving surface}

\section{Nucleate boiling regime}

The heat flux at the onset of boiling was independent of curvilinear position but slightly increased with subcooling. In the nucleate boiling regime, the curvilinear position and subcooling was found to have little influence on the cooling flux (Fig. 6a and 6b).

Fig. $6 \mathrm{c}$ and $6 \mathrm{~d}$ respectively show the influence of jet velocity and the influence of wall velocity on the boiling curves. The cooling flux at the onset of boiling varied slightly with the wall velocity but increased quicker with the speed of the jet. The cooling flux in the fully developed nucleate boiling regime seemed independent of jet velocity and wall velocity. However, it should be noted that near the CHF ( $\Delta T_{\text {sat }}$ around $\left.80-100 \mathrm{~K}\right)$, the dependence of the cooling flux on the speed surface became significant, Fig. 6d. 
This means that in the fully developed nucleate boiling regime heat transfer was found not to depend on hydrodynamics which was expected. This means our data could be fitted with a power law of $\Delta T_{\text {sat }}$. The correlation that best fits our data in the nucleate boiling regime is:

$$
q_{F N B}^{\prime \prime}=2,46 \Delta T_{\text {sat }}^{1,64}
$$

where $q_{F N B}^{\prime \prime}\left(k W / m^{2}\right)$ and $30<\Delta T_{s a t}<60 \mathrm{~K}$

A comparison of the data is shown in the Fig. 7. The closer we got to the CHF, the less data fitted with the equation (17).

\section{CHF}

The CHF can be observed only for $x^{*}>0$ [16]. No cooling was measured for negative values of $x^{*}$. Fig. 8a and $8 \mathrm{~b}$ show the evolution of local CHF for various conditions of speed and subcooling.

The CHF was not found to be uniform throughout the cooling zone and thus there was a maximum that decreased when the wall speed was increased (Fig. 8a). Moreover, the position of that maximum increased when the wall speed was increased and moved towards high $x^{*}$ values. Another point to be noted was that the CHF was also controlled by the water subcooling. In Fig. $8 \mathrm{~b}$, we plotted its spatial evolution for three values of subcooling.

Fig. $8 \mathrm{c}$ and $8 \mathrm{~d}$ show the evolution of CHF for different jet velocities (i.e. increasing the distance between nozzle and wall was equivalent to increase the jet velocity).

We can define two kinds of correlations as follows:

$$
\begin{aligned}
& x_{C H F, \max }=f_{1}\left(V_{j}, V_{s}, \Delta T_{\text {sub }}\right) \\
& q^{\prime \prime}{ }_{C H F}=f_{2}\left(V_{j}, V_{s}, \Delta T_{\text {sub }}, x *\right)
\end{aligned}
$$

A dimensional analysis gave the following relationship: 
$\frac{x_{C H F, \max }}{d}=1,0015 W e^{-0,202} J a^{-0,579}\left(\frac{V_{s}}{V_{n}}\right)^{0,794}\left(\frac{H}{d}\right)^{-0,209}\left(\frac{\rho_{v}}{\rho_{l}}\right)^{-0,247}\left(\frac{h_{l v}}{V_{n}^{2}}\right)^{-0,134}$

with $W e=0,036-0,17 ; J a=\frac{c_{p_{l}} \Delta T_{s u b}}{h_{l v}}=0,033-0,088 ; V_{s} / V_{n}=1,36-3,56 ; H / d=2,5-12,5$; $\rho_{v} / \rho_{l}=8,4.10^{5}-33.10^{5} ; h_{l v} / V^{2}=5.10^{6}-23.10^{6}$.

Fig. 9 compares the positions of the maximum CHF determined experimentally with those calculated using the previous equation (19). This shows that the equation correlates the data with a maximum error of $\pm 12 \%$.

As we knew the position of the maximum CHF, we could estimate the value of CHF upstream and downstream of this position. The correlation given by Miyasaka et al. [15] could be corrected by a factor taking into account the effect of the speed surface $\left(\mathrm{r}^{*}\right)$ as well as the decrease of CHF from its maximum value.

$x<x_{C H F, \max }:$
$q^{\prime \prime}{ }_{C H F}=0,186 h_{l v} \rho_{v}\left(1+0,86 V_{n}^{0,38}\right)\left(1+0,328\left(\frac{\rho_{l}}{\rho_{v}}\right)^{0,56} J a\right)\left(\frac{\sigma g\left(\rho_{l}-\rho_{v}\right)}{\rho_{v}{ }^{2}}\right)^{0,25}\left(1+\frac{x}{d}\right)^{0,317}\left(1+r^{*}\right)^{-1,926}$

$\boldsymbol{x}>x_{C H F, \max }:$

$q_{C H F}^{\prime \prime}=0,186 h_{l v} \rho_{v}\left(1+0,86 V_{n}^{0,38}\right)\left(1+0,328\left(\frac{\rho_{l}}{\rho_{v}}\right)^{0,56} J a\right)\left(\frac{\sigma g\left(\rho_{l}-\rho_{v}\right)}{\rho_{v}{ }^{2}}\right)^{0,25}\left(1+\frac{x}{d}\right)^{-0,0486}(1+r *)^{-0,83}$

with $V_{n}=0,32-0,69 \mathrm{~m} / \mathrm{s} ; \Delta T_{\text {sub }}=18-50 \mathrm{~K}$ et $r^{*}=0,5-1,25$.

The correlations correspond to our experimental data with a maximum deviation of $\pm 20 \%$ (Fig. $10 \mathrm{a}$ and $10 \mathrm{~b}$ )

\subsection{Comparisons with existing correlations}

It is clear that heat fluxes were strongly modified in all the boiling regimes when the wall was moving. If we compare our results with the correlations given in Section 1, the correlations used 
so far for static surfaces lead to an overestimation of heat transfers for a moving surface. Fig. 11a and $11 \mathrm{~b}$ show our comparisons of the proposed correlations for nucleate boiling (equation 18) and CHF (equation 22) with the findings of Wolf et al. [38] (equation 13) and Miyasaka et al. [15] (equation 12b). The question was why heat transfer is overestimated by previous correlations? It is surprising that heat transfer is widely modified for nucleate boiling because as we showed in section 1 , most of the correlations used for nucleate boiling do not usually take any hydrodynamics effects into account. To our knowledge, only the equation proposed by Filipovic et al. [39-40] (correlation for a static surface) takes into account the velocity of the jet, the subcooling, the diameter of the nozzle and superheat but this also leads to the heat flux in the case of nucleate boiling for moving system being overestimated.

CHF was also overestimated by the correlation given by Myasaka et al. [15]. In that particular case, this is less surprising because as Critical Heat Flux occurs, the amount of vapour which is produced at the wall may be carried by the moving wall which leads to heat transfer being limited. 


\section{Concluding remarks}

This paper presents new results regarding the water cooling of a hot moving strip which was initially at a temperature around $600^{\circ} \mathrm{C}$. Special instrumentations and signal treatment were set up and used to obtain the time-dependent surface temperature and extracted heat flux. The findinds of this experimental study could be used for control cooling systems in ROT. The main findings of this study are as follows:

1. The cooling rates were significantly different for moving surfaces as compared with static surface. We observed the same spatial pattern with film boiling, shoulder of flux, transition boiling, CHF and finally nucleate boiling.

2. The main difference was observed in the shoulder of flux region where the moving of the surface induced a collapse of the heat flux.

3. Correlations for nucleate boiling and $\mathrm{CHF}$ are available for wide range of operating conditions. Surface velocity is a very sensitive parameter for CHF.

4. Finally, we conclude that further experiments are needed to explain the collapse of the shoulder of flux and to predict the rewetting $\left(\mathrm{T}_{\mathrm{MFB}}\right)$ of the surface for high superheats. 


\section{References}

[1] S. Serajzadeh, Prediction of temperature distribution and phase transformation on the runout table in the process of hot strip rolling, Applied Mathematical Modelling 27 (2003) 861-875

[2] Y.K Sun, D. Wu, Effect of Ultra-Fast Cooling on Microstructure of Large Section Bars of Bearing Steel, Journal of Iron and Steel Research, International, Volume 16, Issue 5, September 2009, Pages 61-65, 80

[3] R.W.K. Honeycombe, Steels: Microstructure and Properties, Edward Arnold, London, 1981.

[4] N. Hatta, J. Kokado, H. Takuda, J. Harada, K. Hiraku, Modelling for cooling process of a hot plate by a laminar water bar, Steel Research 55 (1984) 143-148.

[5] M. Gradeck, A. Kouachi, A. Dani, D. Arnoult and J.L. Borean, 2006, Experimental and numerical study of the hydraulic jump of an impinging jet on a moving surface, Experimental Thermal and Fluid Science, 30, 193-201.

[6] Cho M.J., Thomas B.G. and Lee P. J., "Three-Dimensional Numerical Study of Impinging Water Jets in Runout Table Cooling Processes", Metallurgical and Materials Transactions B, Volume 39, Number 4, 2008.

[7] Monde, M., Kusuda, H., Uehara, H., "Burnout heat flux in saturated forced convection boiling with two or more impinging jets”, Transactions of the JSME 46, 1834-1843, 1980.

[8] Franco G. "Boiling heat transfer during cooling of a hot moving steel plate by multiple top jets", PhD of The University Of British Columbia, Vancouver, December 2008.

[9] Ishigai S., Nakanishi A. and Ochi T., 1978, Boiling heat transfer for a plane water jet impinging on a hot surface, 6th International Heat transfer Conference, 1, FB 30, 445-450.

[10] Ochi T., Nakanishi S., Kaji M., Ishigai S., 1984, Multi-phase and Heat Transfer III. Part A: Fundamentals - Cooling of a hot plate with an impinging circular water jet, Elsevier Science Publishers B.V., Amsterdam, 671-681. 
[11] Hall E. D., Incropera F. P., Viskanta R., Jet impingement boiling from a circular freesurface jet during quenching: Part1-single-phase jet, J. of Heat transfer, Vol. 123, 901-910, 2001. [12] Wolf, D.H., 1993, Turbulent development in a free surface jet and impingement boiling heat transfer, Ph. D., Purdue University.

[13] Robidou H., Auracher H., Gardin, P., Lebouché M., 2002, Controlled cooling of a hot plate with a water jet, Exp. Thermal and Fluid Science, 26, Issues 2-4, June 2002, 123-129

[14] Aloke Kumar Mozumder, Masanori Monde, Peter Lloyd Woodfield, Md. Ashraful Islam, 2006, Maximum heat flux in relation to quenching of a high temperature surface with liquid jet impingement, Int. J. of Heat and Mass Transfer, Volume 49, Issues 17-18, 2877-2888

[15] Miyasaka, Y., Inada, S., Owase, Y., 1980, Critical heat flux and subcooled nucleate boiling in transient region between a two-dimensional water jet and a heated surface, J. Chem. Eng. Japan, 13, 29-35

[16] Gradeck M., Kouachi A., Lebouché M., Volle F., Maillet D., Borean J.L., "Boiling curves in relation to quenching of a high temperature moving surface with liquid jet impingement", Int. J. of Heat and Mass Transfer, Volume 52, Issues 5-6, February 2009, 1094-1104.

[17] Yi Zheng, Shaoyuan Li, Xiaobo Wang, Distributed model predictive control for plantwide hot-rolled strip laminar cooling process, Journal of Process Control 19 (2009) 1427-1437 [18] Ananya Mukhopadhyay, Sudipta Sikdar, Implementation of an on-line run-out table model in a hot strip mill, Journal of Materials Processing Technology 169 (2005) 164-172 [19] H.B. Xie, Z.Y. Jiang, X.H. Liu, G.D. Wang, A.K. Tieu, Prediction of coiling temperature on run-out table of hot strip mill using data mining, Journal of Materials Processing Technology 177 (2006) 121-125

[20] D.A. Zumbrunnen, F.P. Incropera, R. Viskanta, Method and apparatus for measuring heat transfer distributions on moving and stationary plates cooled by a planar liquid jet, Exp. Thermal Fluid Sci., 1990, vol. 3, pp. 202-213. 
[21] D.A. Zumbrunnen, F.P. Incropera, R. Viskanta, The effect of surface motion on forced convection film boiling heat transfer, J. of Heat transfer ASME, 1989, vol. 111, pp. 760-766.

[22] Filipovic, Jovan Vladimir, Film boiling over a moving horizontal surface, Ph.D., Purdue University, 1994.

[23] Liu Z-H.and Wang J., Study on film boiling heat transfer for water jet impinging on high temperature flat plate, International Journal of Heat \& Mass Transfer, 2001, Vol. 44, 2475-2481.

[24] Liu Z-H., Prediction of minimum heat flux for water jet boiling on a hot plate, Journal of thermophysics and heat transfer, vol. 17, n², April-June 2003.

[25] Robidou H, Etude expérimentale du refroidissement diphasique à haute température par jet d'eau impactant, Thèse de doctorat, Université Henri Poincaré, Nancy I, 2000

[26] Hatta N., Kokado J-I., Takuda H., Harada J. and Hiraku K., Predictable modeling for coolings process of a hot steel plate by a laminar water bar, Arch. Eisenhüttenwes. 55 (1984), Nr. 4, April.

[27] Kokado J-I., Hatta N., Takuda H., Harada J. and Yasuhira N., An analysis of film boiling phenomena of subcooled water spreading radially on hot steel plate, Arch. Eisenhüttenwes. Vol. 55, №3, März 1984.

[28] Hatta N. and Osakabe H., "Numerical modeling for cooling process of a moving hot plate by a laminar water curtain”, ISIJ International, 1995, vol. 29, N 11, pp. 919-925.

[29] N. Karwa, T. Gambaryan-Roisman, P. Stephan, C. Tropea, A hydrodynamic model for subcooled liquid jet impingement at the Leidenfrost condition, International Journal of Thermal Sciences (2011), doi:10.1016/j.ijthermalsci.2011.01.021

[30] Berenson, P. J.; 1961, "Film Boiling Heat Transfer from a Horizontal Surface", J. Heat Transfer, V. 83, No 3, pp. 351-358.

[31] Kalinin E. K., Berlin I. I. and Kostiouk V. V., "Transition boiling heat transfer", Advances in heat transfer, volume 18, Academic Press, 1987. 
[32] Pan Chin, Hwang J. Y. and Lin, T. L. "The mechanism of heat transfer in transition boiling”, Int. J. Heat Mass Transfer, Vol. 32, N7, pp. 1337-1349, 1989.

[33] Nagai N. and Nishio S., "Leidenfrost Temperature on an Extremely Smooth Surface", Experimental Thermal and Fluid Science 1996; 12:373-379.

[34] Ohtake H. and Koizumi Y., "Derivations of correlation and liquid-solid contact model of transition boiling heat transfer”, JSME International Journal, Series B, Vol. 49, No. 2, 2006.

[35] Monde, M., Kusuda, H., Uehara, H., "Burnout heat flux in saturated forced convection boiling with two or more impinging jets", Transactions of the JSME 46, 1834-1843, 1980.

[36] Mitsutake Y., Monde M., "Ultra High Critical Heat Flux During Forced Flow Boiling Heat Transfer With an Impinging Jet", Journal of Heat Transfer, December 2003, Volume 125, Issue 6, pp. 1038-1045.

[37] Hammad J.A., Mitsutake Y. and Monde M., "Movement of maximum heat flux and wetting front during quenching of hot cylindrical block", International Journal of Thermal Sciences, Volume 43, Issue 8, August 2004, Pages 743-752.

[38] Wolf D.H., Incropera F.P. and Viskanta R., "Local jet impingement boiling heat transfer", Int. J. Heat Transfer, Vol. 39, No. 7, pp. 1395-1406, 1996.

[39] Filipovic J., Viskanta R. and Incropera F.P., "Cooling of a moving steel strip by an array of round jets”, 35th MWSP Conf. Proc, ISS-AIME, vol. XXXI, p. 317, 1994.

[40] Filipovic J., Viskanta R., Incropera F.P. and Veslocki T.A., "Cooling of a moving steel strip by an array of round jets”, Steel Research, vol. 65, N 12, 1994.

[41] F Volle, D Maillet, M Gradeck, A Kouachi, M Lebouché, Practical application of inverse heat conduction for wall condition estimation on a rotating cylinder, International Journal of Heat and Mass Transfer, Volume 52, Issues 1-2, 15 January 2009, Pages 210-221. 
[42] Kouachi A., «Étude expérimentale de l'ébullition convective d'un jet d'eau plan impactant une surface mobile portée à hautes températures », Thèse de Doctorat de l'Université de Nancy 1, Nancy, 2006. ddc :620. http://www.scd.uhp-nancy.fr/docnum/SCD_T_2006_0136... [43] Maillet D., André S., Batsale J.C, Degiovanni A. and Moyne C., 2000, Thermal quadrupoles : solving the heat equation through integral transforms, John Wiley and Sons, UK.

[44] F.Volle, D.Maillet, M. Gradeck and M.Lebouché, 2008, Semi-analytical inverse heat conduction on a rotating cylinder with Laplace and Fourier transforms, Inverse Problem in Science and Engineering-IPSE-Cambridge, Vol. 16, n5, 655-674

[45] F Volle, M Gradeck, A Kouachi, D Maillet, M Lebouché, Inverse heat conduction applied to the measurement of heat fluxes on a rotating cylinder: comparison between an analytical and a numerical technique, J. Heat Transfer - August 2008-Volume 130, Issue 8, 081302 (8 pages), doi:10.1115/1.2928013

[46] N. Seiler-Marie, J.M. Seiler, O. Simonin, Transition boiling at jet impingement, International Journal of Heat and Mass Transfer 47 (2004) 5059-5070 
Table 1: Experimental conditions of the cited works

\begin{tabular}{|c|c|c|c|c|c|c|}
\hline Authors & Experiment & Liquid & Jet & Surface & Running conditions & Regimes \\
\hline Ishigai et al. [9] & Transient & water & $\begin{array}{l}\text { Free } \\
\text { Planar } \\
50 \times 6.2 \mathrm{~mm}^{2}\end{array}$ & $\begin{array}{l}(20 \text { or } 80) \times 12 \mathrm{~mm}^{2} \\
\text { Stanless steel }\end{array}$ & $\begin{array}{l}1 \leq V_{J} \leq 3.2 \mathrm{~m} / \mathrm{s} \\
5 \leq \Delta T_{\text {sub }} \leq 55 \mathrm{~K}\end{array}$ & $\begin{array}{l}\text { Nucleate boiling } \\
\text { Transition boiling } \\
\text { Film boiling }\end{array}$ \\
\hline Ochi et al. [10] & Transient & Water & $\begin{array}{l}\text { Free } \\
\text { Circular } \\
\varnothing 5,10 \text { and } 20 \mathrm{~mm} \\
\end{array}$ & $\begin{array}{l}210 \times 50 \mathrm{~mm}^{2} \\
\text { Stanless steel }\end{array}$ & $\begin{array}{l}2 \leq V_{J} \leq 7 \mathrm{~m} / \mathrm{s} \\
5 \leq \Delta T_{\text {subB }} \leq 80 \mathrm{~K}\end{array}$ & $\begin{array}{l}\text { Nucleate boiling } \\
\text { Transition boiling } \\
\text { Film boiling }\end{array}$ \\
\hline Kokado et al. [27] & Transient & Water & $\begin{array}{l}\text { Free } \\
\text { Circular } \\
\varnothing 10 \mathrm{~mm} \\
\end{array}$ & $\begin{array}{l}2000 \times 10 \mathrm{~mm}^{2} \\
\text { Stanless steel }\end{array}$ & $\begin{array}{l}1 \leq Q_{V} \leq 71 / \mathrm{min} \\
T_{L}=20^{\circ} \mathrm{C}\end{array}$ & $\begin{array}{l}\text { Wetting } \\
\text { Non wetting }\end{array}$ \\
\hline Mitsutake et al. [36] & Transient & Water & $\begin{array}{l}\text { Free } \\
\text { Circular } \\
\varnothing 2 \mathrm{~mm}\end{array}$ & $\begin{array}{l}\text { Width } 4 \mathrm{~mm} \\
\text { Thickness } 0.1 \mathrm{~mm} \\
\text { Stanless steel } \\
\mathrm{Ni}\end{array}$ & $\begin{array}{l}5 \leq V_{J} \leq 60 \mathrm{~m} / \mathrm{s} \\
0.1 \leq P \leq 1.3 \mathrm{MPa} \\
T_{L}=20^{\circ} \mathrm{C}\end{array}$ & $\mathrm{CHF}$ \\
\hline Wolf [12] & $\begin{array}{l}\text { Stationary } \\
\text { Imposed heat } \\
\text { flux }\end{array}$ & Water & $\begin{array}{l}\text { Free } \\
\text { Planar } \\
10 \times 105 \mathrm{~mm}^{2}\end{array}$ & $\begin{array}{l}119 \times 35.7 \mathrm{~mm}^{2} \\
\text { Alloy Ni-Cr-W-Mo }\end{array}$ & $\begin{array}{l}10 \leq x \leq 90 \mathrm{~mm} \\
2 \leq V_{J} \leq 5 \mathrm{~m} / \mathrm{s} \\
\Delta T_{\text {sub }}=50 \mathrm{~K} \\
0.25 \leq q^{\prime \prime} \leq 6.34 \mathrm{MW} / \mathrm{m}^{2}\end{array}$ & $\begin{array}{l}\text { Forced convection } \\
\text { Onset of nucleate } \\
\text { boiling } \\
\text { Nucleate boiling }\end{array}$ \\
\hline Miyasaka et al. [15] & Stationary & Water & $\begin{array}{l}\text { Free } \\
\text { Planar } \\
10 \times 32 \mathrm{~mm}^{2} \\
\end{array}$ & $\begin{array}{l}4 \mathrm{x} 8 \mathrm{~mm}^{2} \\
\mathrm{Pt}\end{array}$ & $\begin{array}{l}1.1 \leq V_{J} \leq 15.3 \mathrm{~m} / \mathrm{s} \\
T_{L}=15^{\circ} \mathrm{C}\end{array}$ & $\begin{array}{l}\text { Forced convection } \\
\text { Nucleate boiling } \\
\text { CHF }\end{array}$ \\
\hline Miyasaka et al. [15] & Stationary & Water & $\begin{array}{l}\text { Free } \\
\text { Planar } \\
10 \times 32 \mathrm{~mm}^{2}\end{array}$ & $\begin{array}{l}\varnothing 1.5 \mathrm{~mm} \\
\mathrm{Pt}\end{array}$ & $\begin{array}{l}1.1 \leq V_{J} \leq 15.3 \mathrm{~m} / \mathrm{s} \\
T_{L}=15^{\circ} \mathrm{C}\end{array}$ & $\begin{array}{l}\text { Nucleate boiling } \\
\text { CHF } \\
\text { Transition boiling }\end{array}$ \\
\hline Robidou et al. [13] & $\begin{array}{l}\text { Stationary } \\
\text { Controlled } \\
\text { temperature }\end{array}$ & Water & $\begin{array}{l}\text { Free } \\
\text { Planar } \\
1 \times 9 \mathrm{~mm}^{2} \\
\end{array}$ & $\begin{array}{l}10 \times 104 \mathrm{~mm}^{2} \\
\mathrm{Ni} \text { on } \mathrm{Cu}\end{array}$ & $\begin{array}{l}0.46 \leq V_{n} \leq 0.9 \mathrm{~m} / \mathrm{s} \\
5 \leq \Delta T_{s u b} \leq 17 \mathrm{~K}\end{array}$ & All regimes \\
\hline $\begin{array}{l}\text { Kouachi [42] } \\
\text { Gradeck et al [16] }\end{array}$ & Transient & Water & $\begin{array}{l}\text { Free } \\
\text { Planar } \\
4 \times 180 \mathrm{~mm}^{2} \\
\end{array}$ & $\begin{array}{l}\text { Rotating cylinder } \\
\mathrm{Ni} \\
\varnothing 175 \mathrm{~mm} \\
\end{array}$ & $\begin{array}{l}0.32 \leq V_{n} \leq 0.69 \mathrm{~m} / \mathrm{s} \\
0.5 \leq r^{*} \leq 1.25 \mathrm{~m} / \mathrm{s} \\
18 \leq \Delta T_{\text {sub }} \leq 50 \mathrm{~K}\end{array}$ & All regimes \\
\hline
\end{tabular}




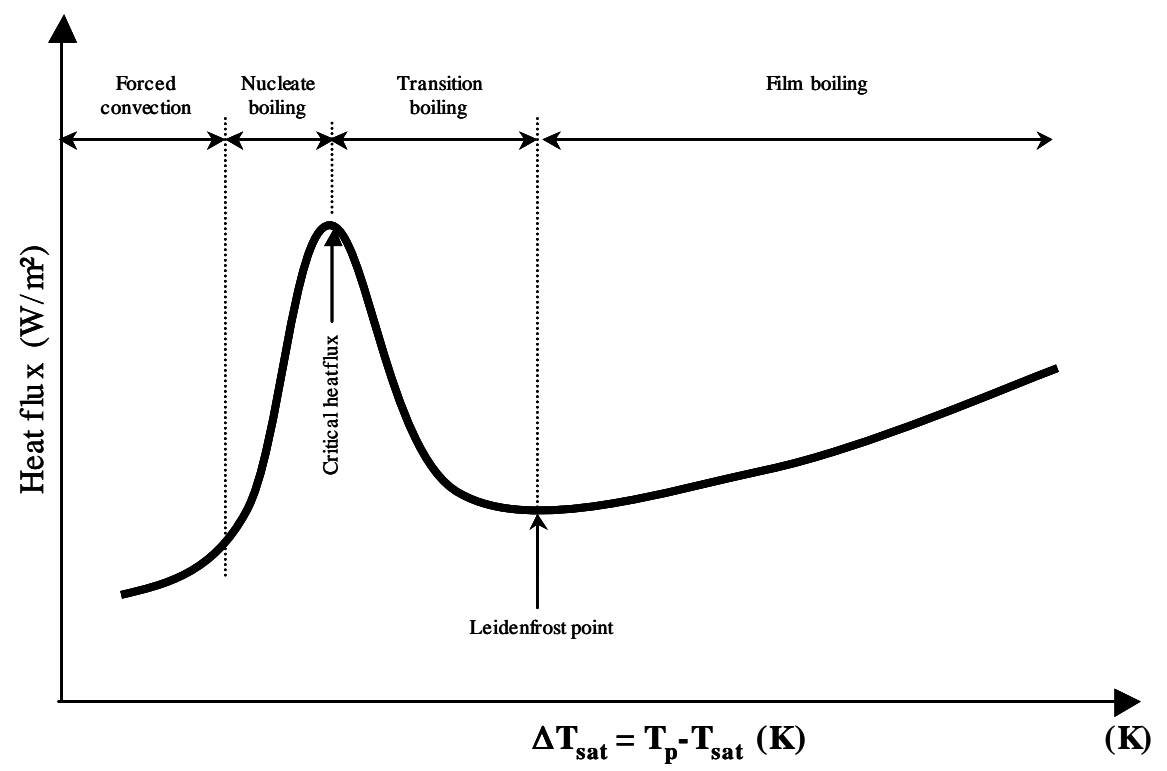

(a)

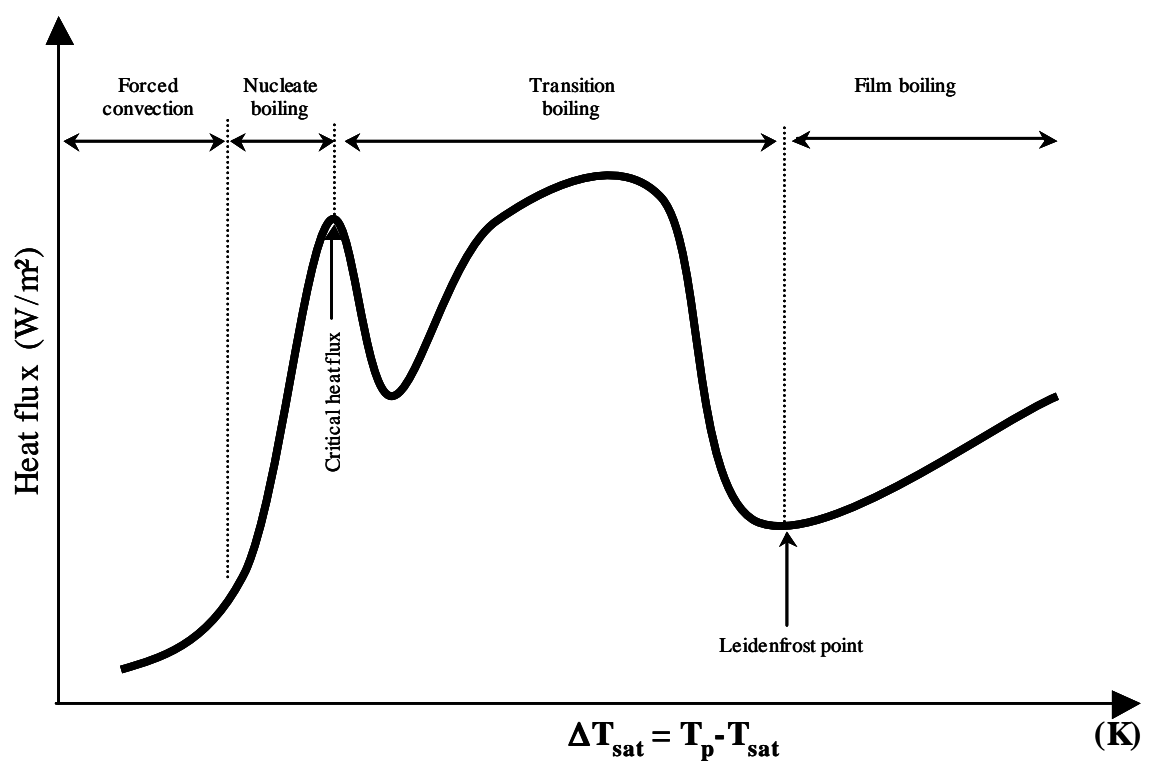

(b)

Figure 1 : Shape of the boiling curve in impinging jet experiments

(a) parallel flow zone of the jet (b) impinging zone of the jet 


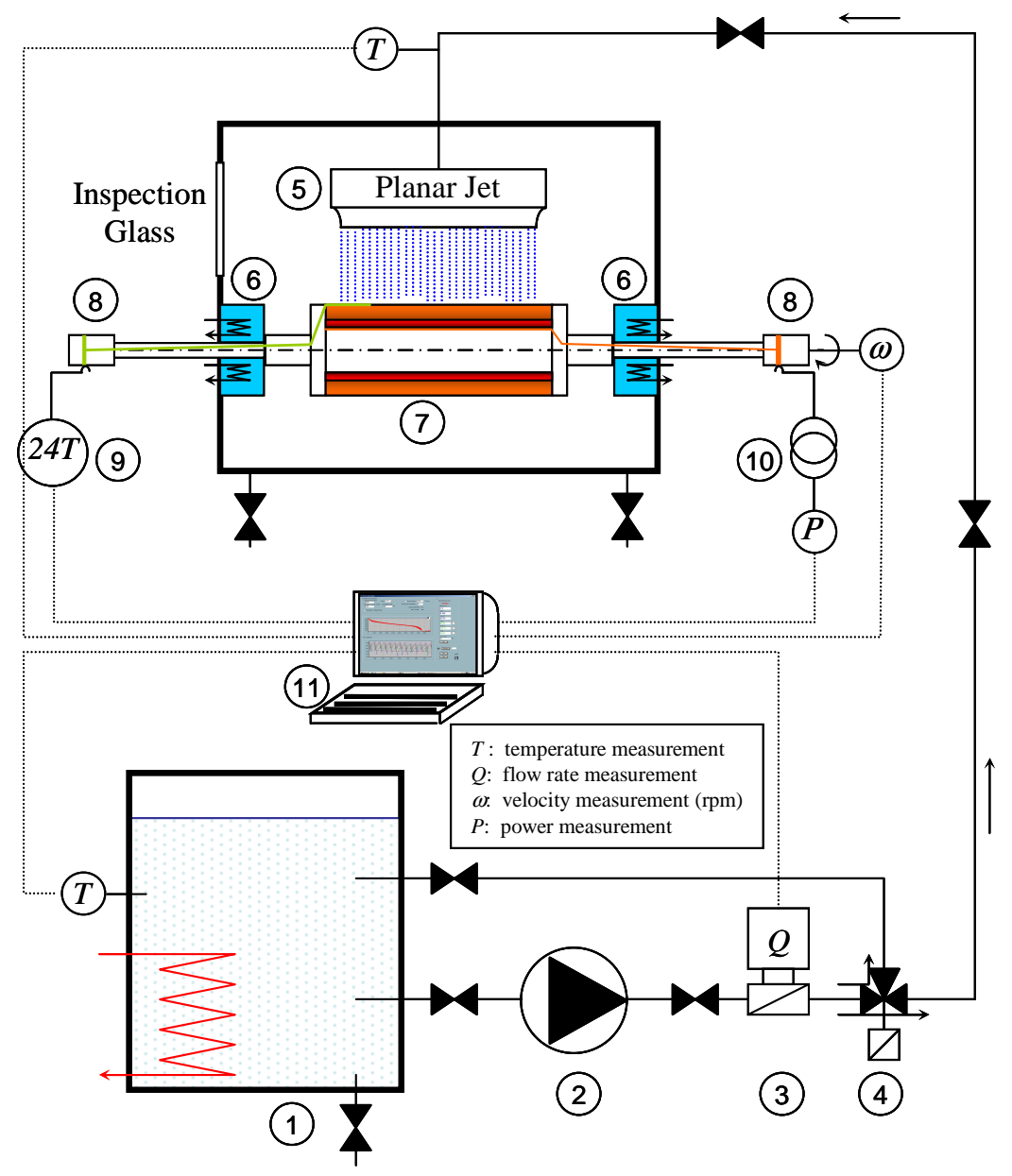

Figure 2a : Schematic of the experimental set-up [42]

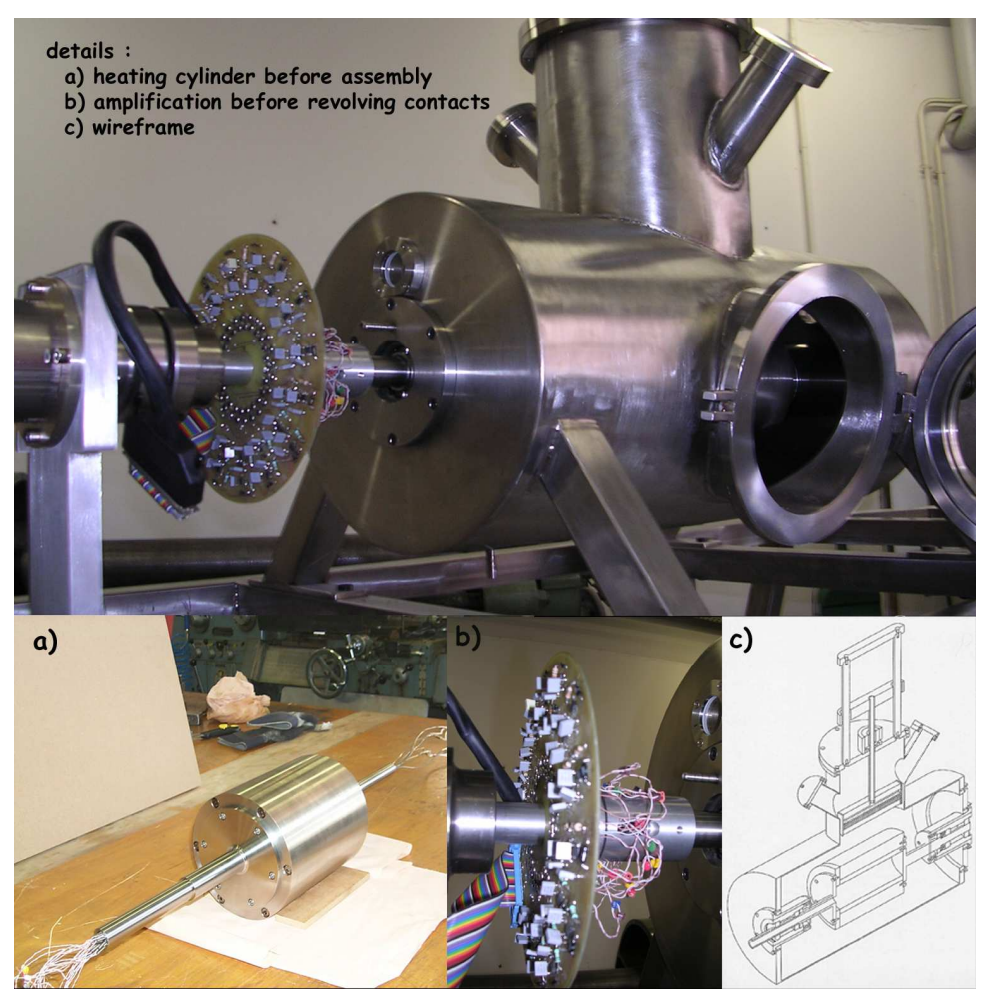

Figure $2 b$ : details of the experimental set-up [42] 


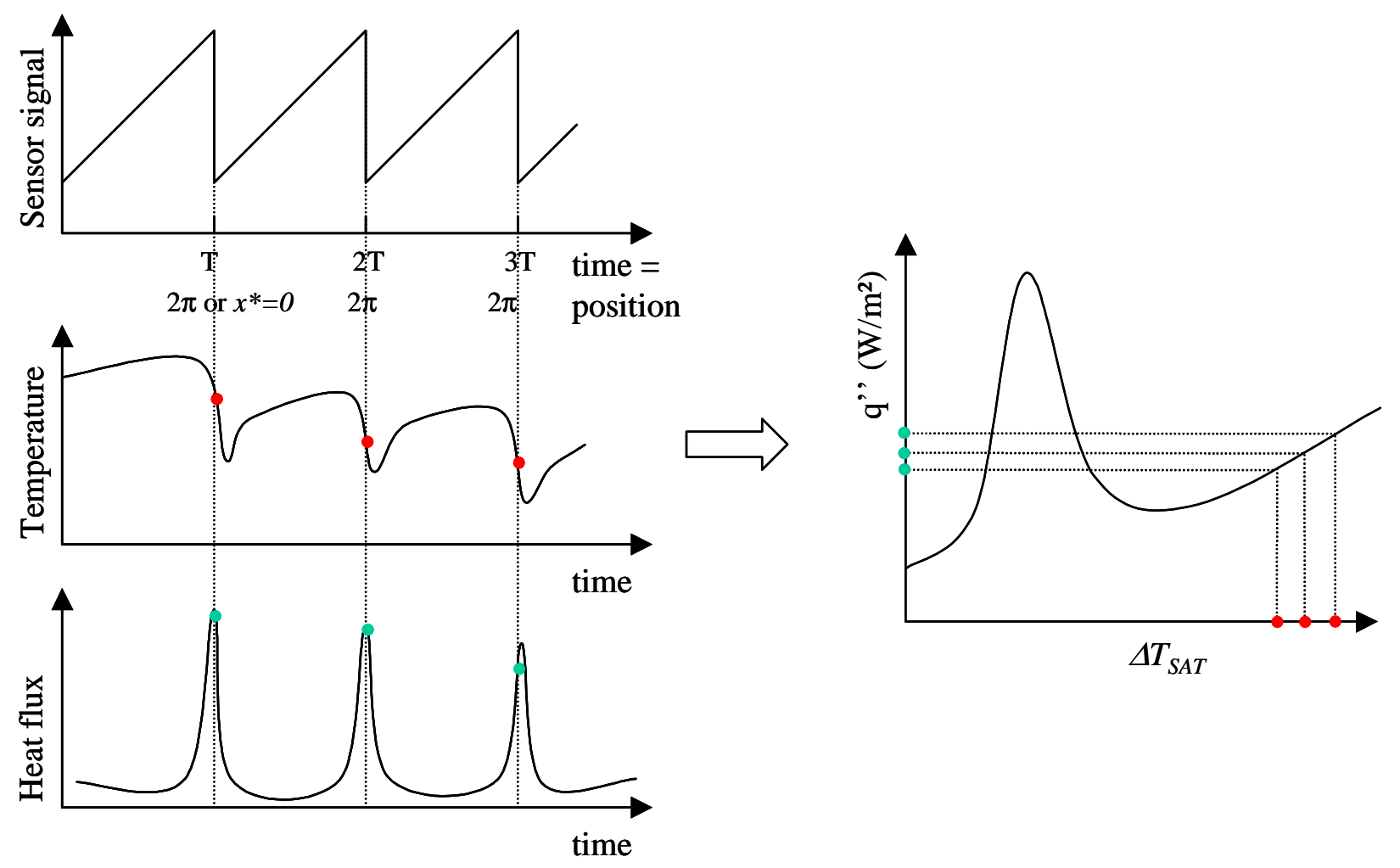

Figure 3 : Building of the boiling curves 


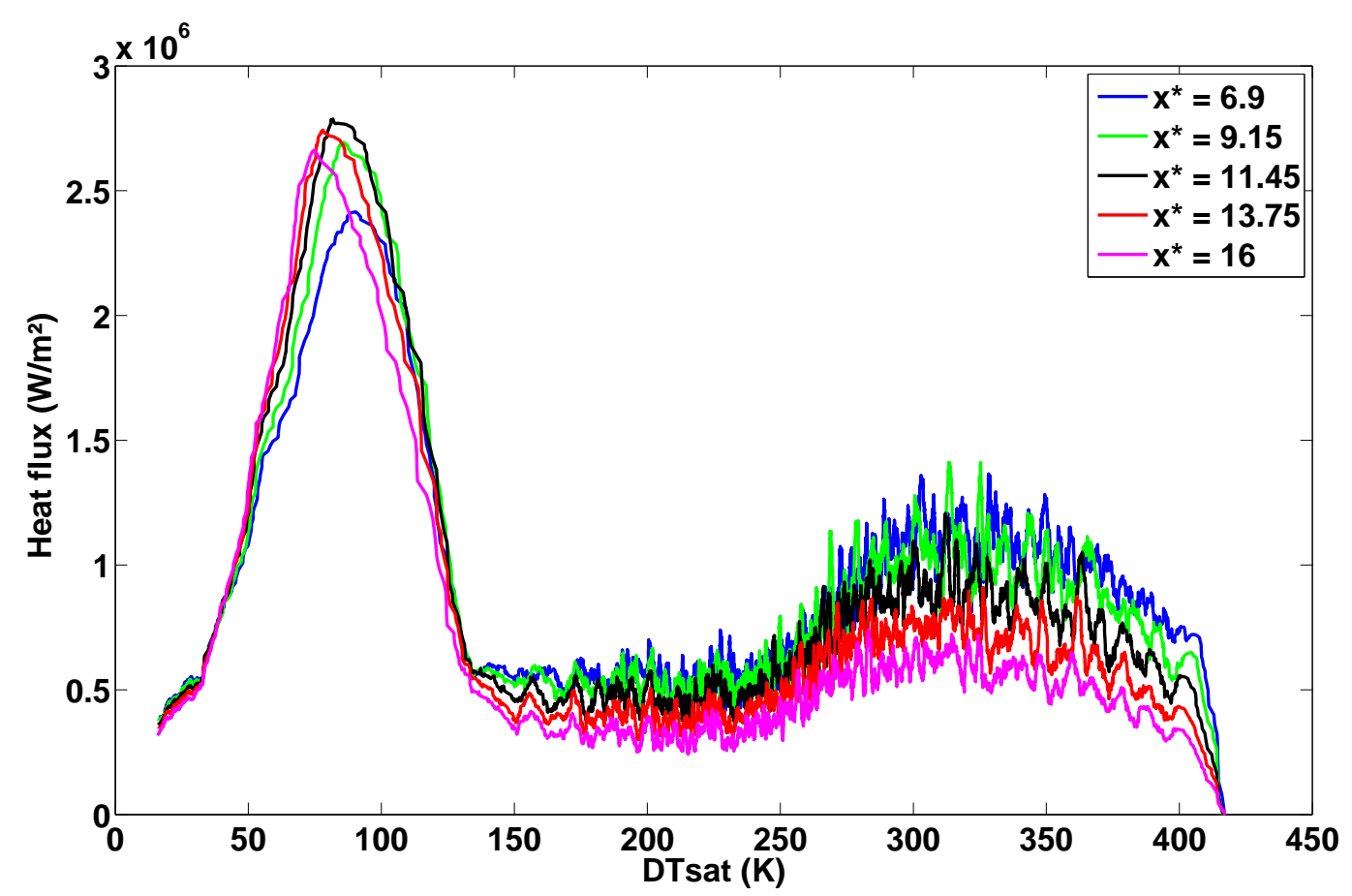

(a)

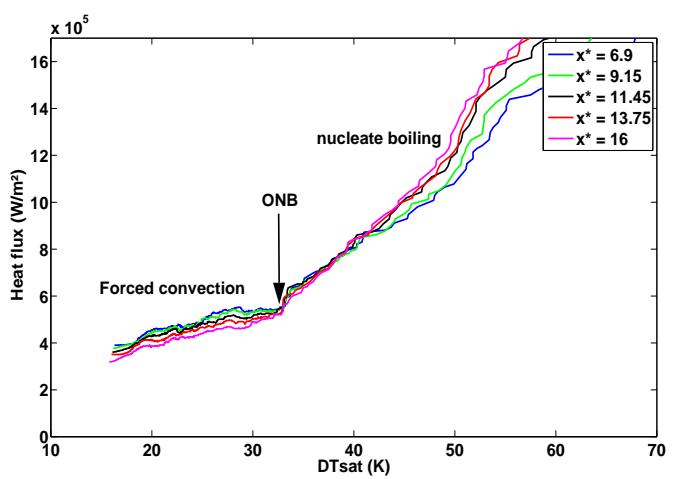

(b)

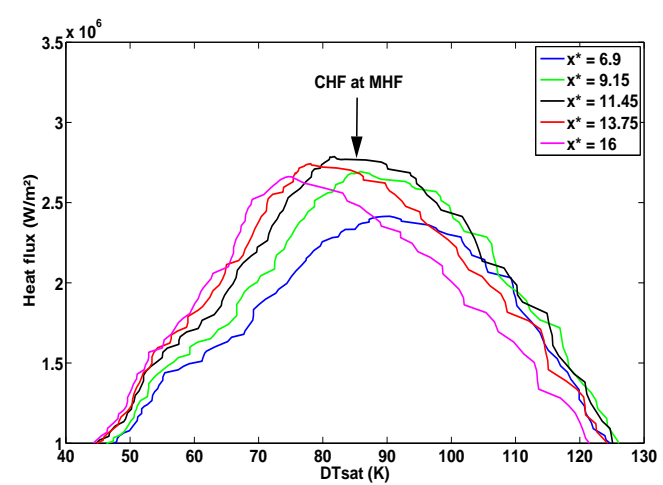

(c)

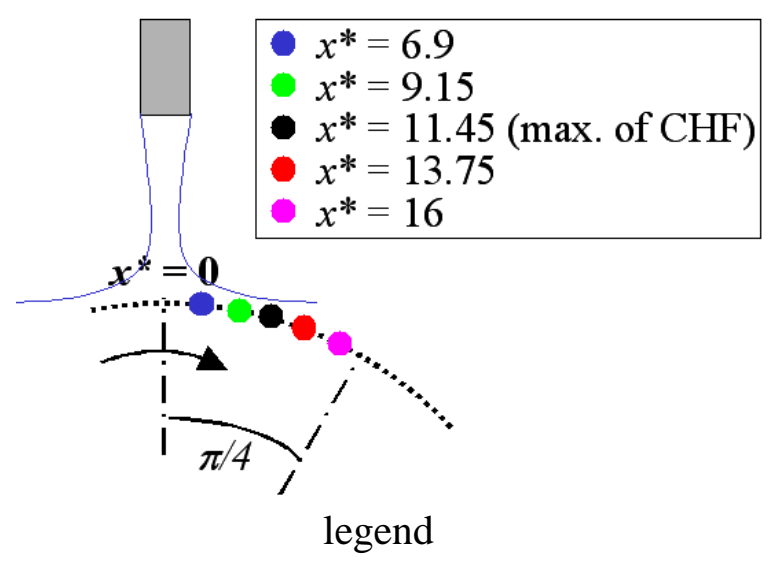

Figure 4 : local boiling curves from [16], $\Delta T_{\text {sub }}=34 K ; u_{j}=1,06 \mathrm{~m} / \mathrm{s}-u^{*}=1,25$ 


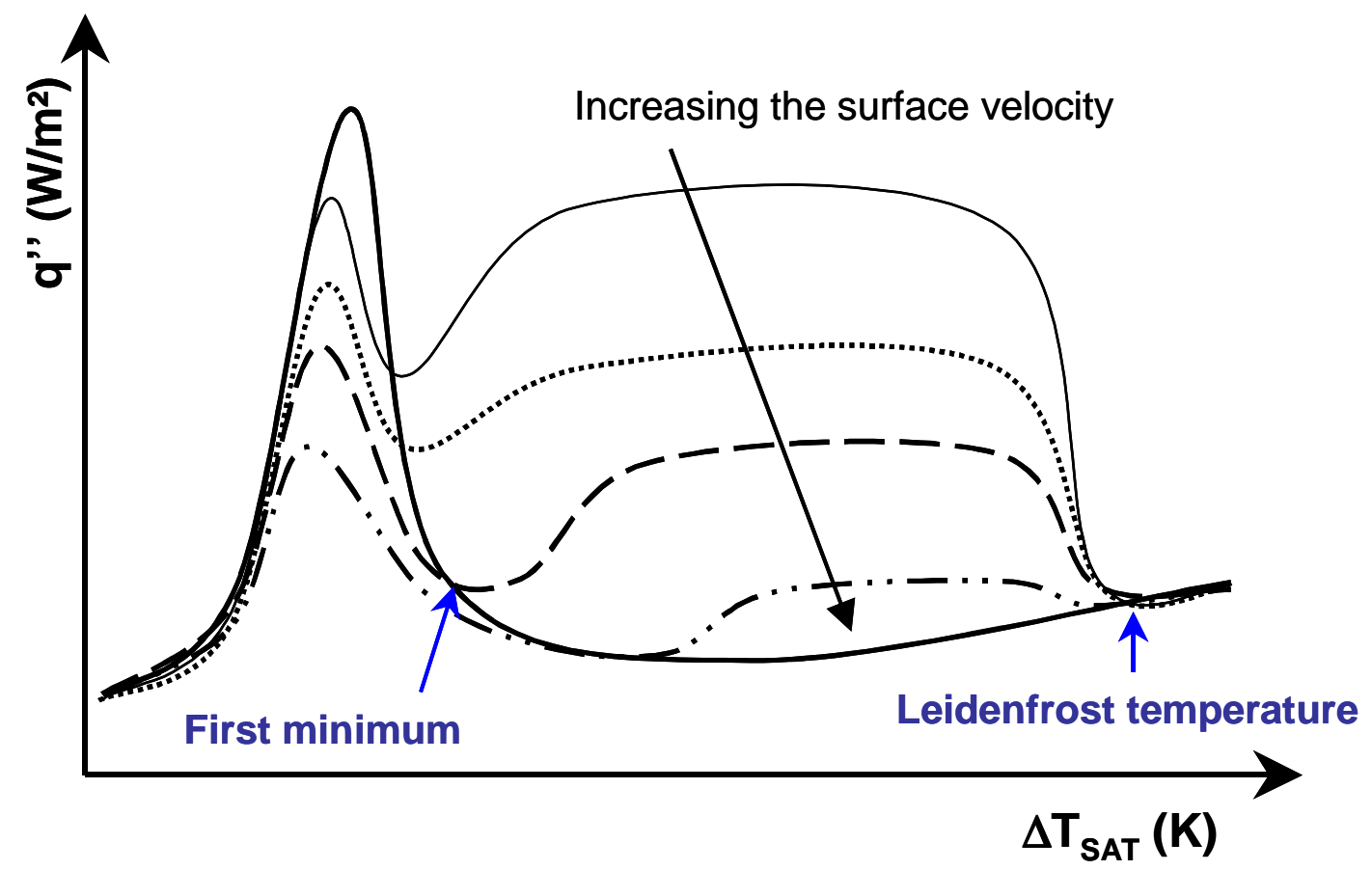

Figure 5 : shape of the local boiling curves with a moving surface 


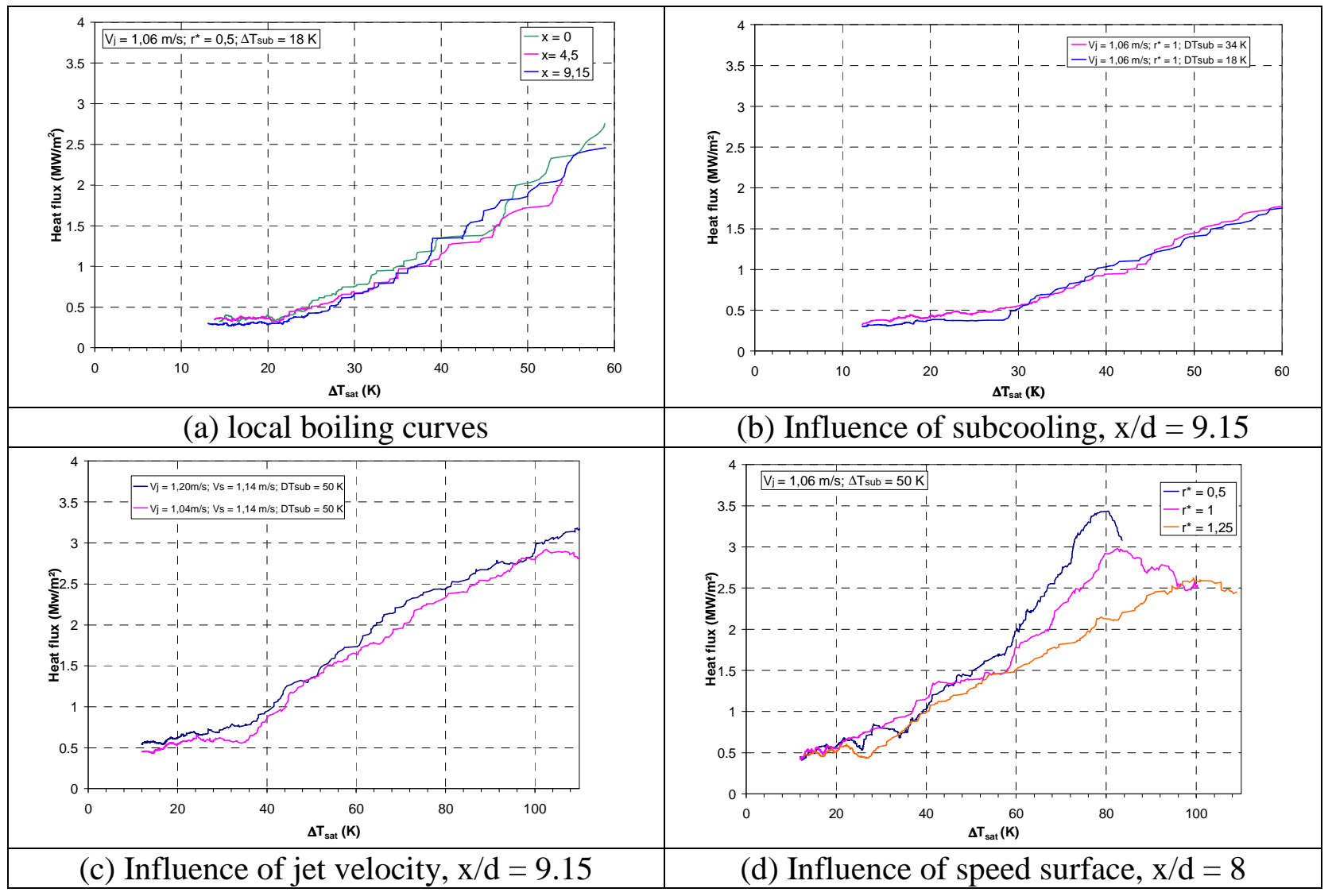

Figure 6 : local evolution of boiling curves in nucleate boiling regime 


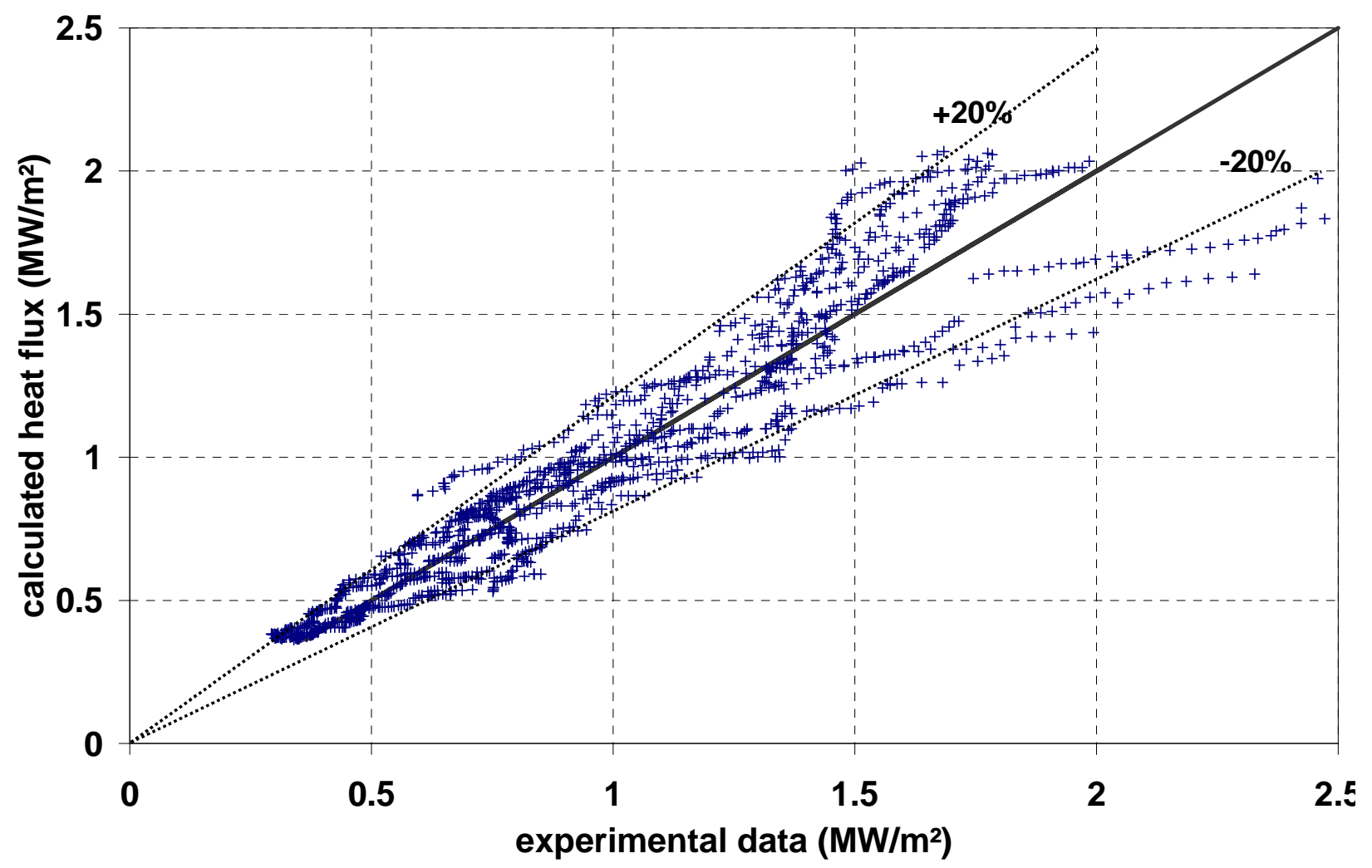

Figure 7 : Comparison between experimental data and correlation (18) 

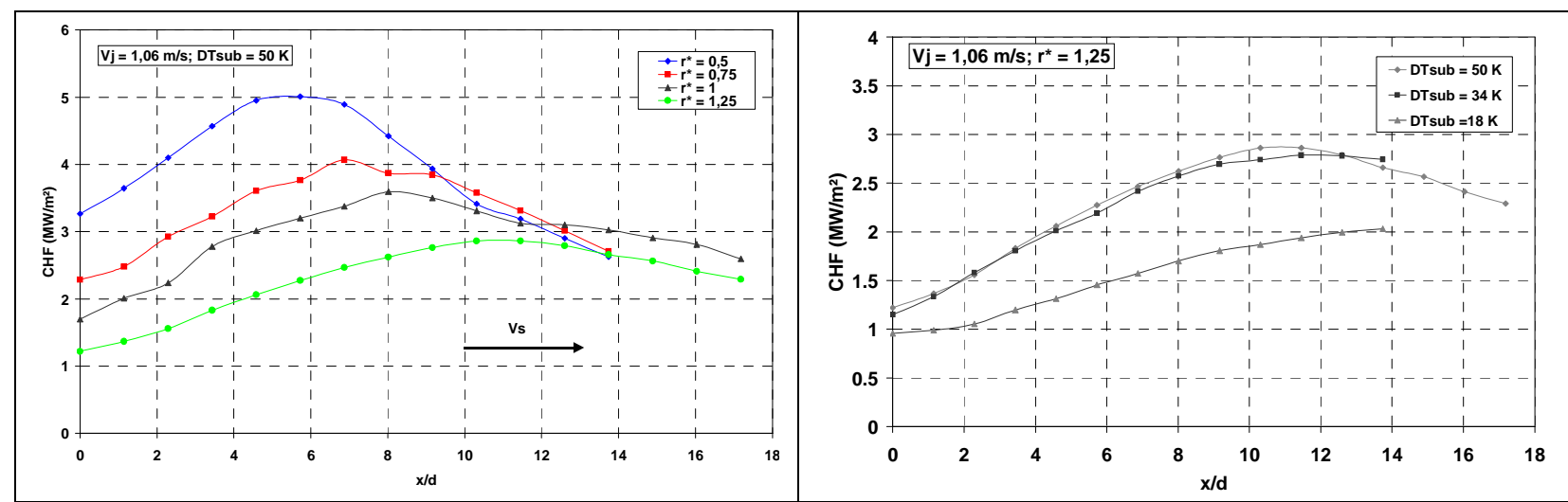

(a) influence of the surface velocity

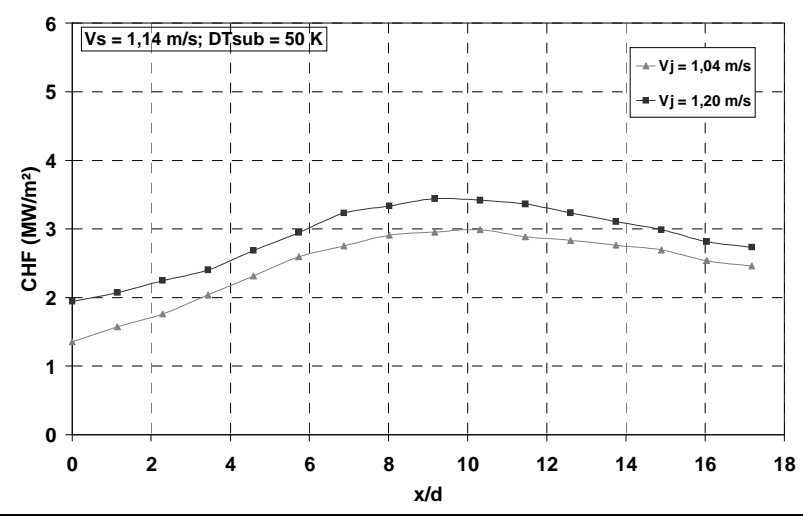

(c) influence of the jet velocity (b) influence of the subcooling

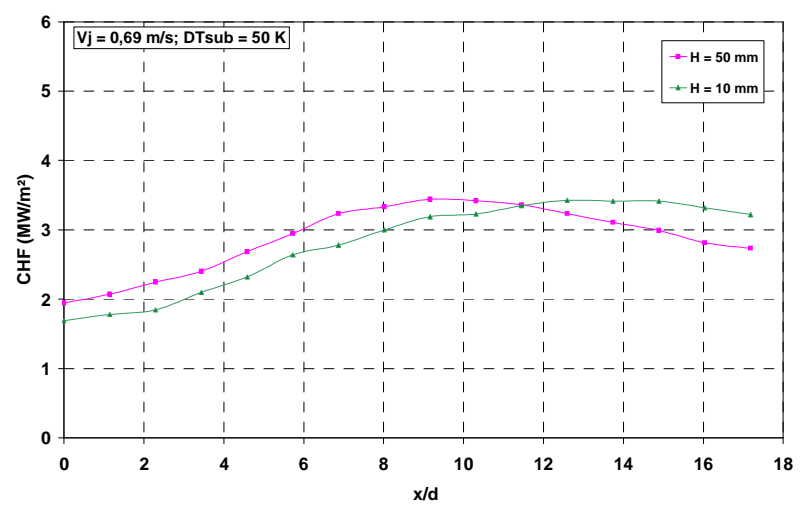

(d) influence of the nozzle distance

Figure 8 : local evolutions of the $\mathrm{CHF}$ 


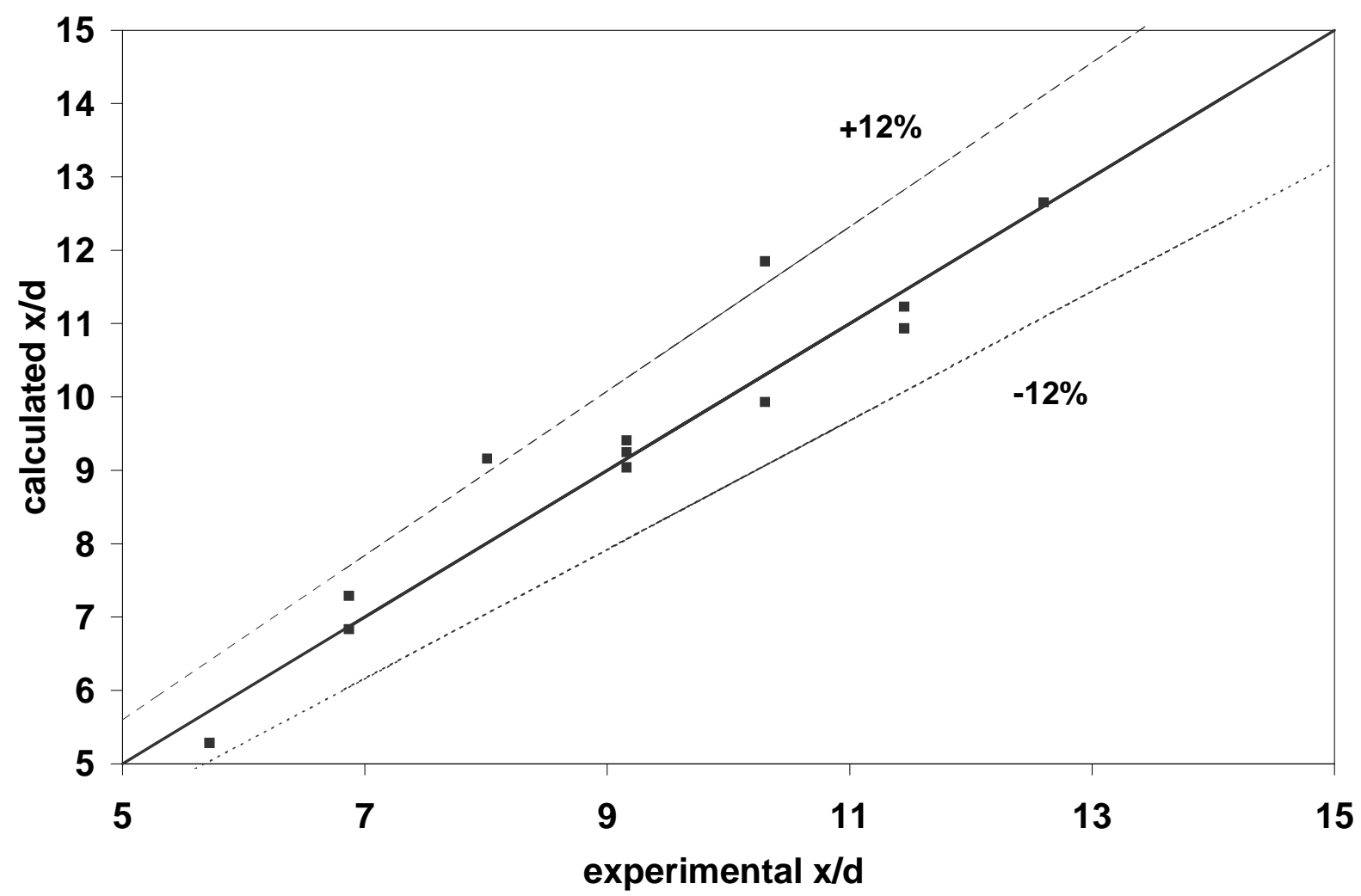

Figure 9 : Comparison between data and calculated $x_{C H F, \max }$ using (21) 


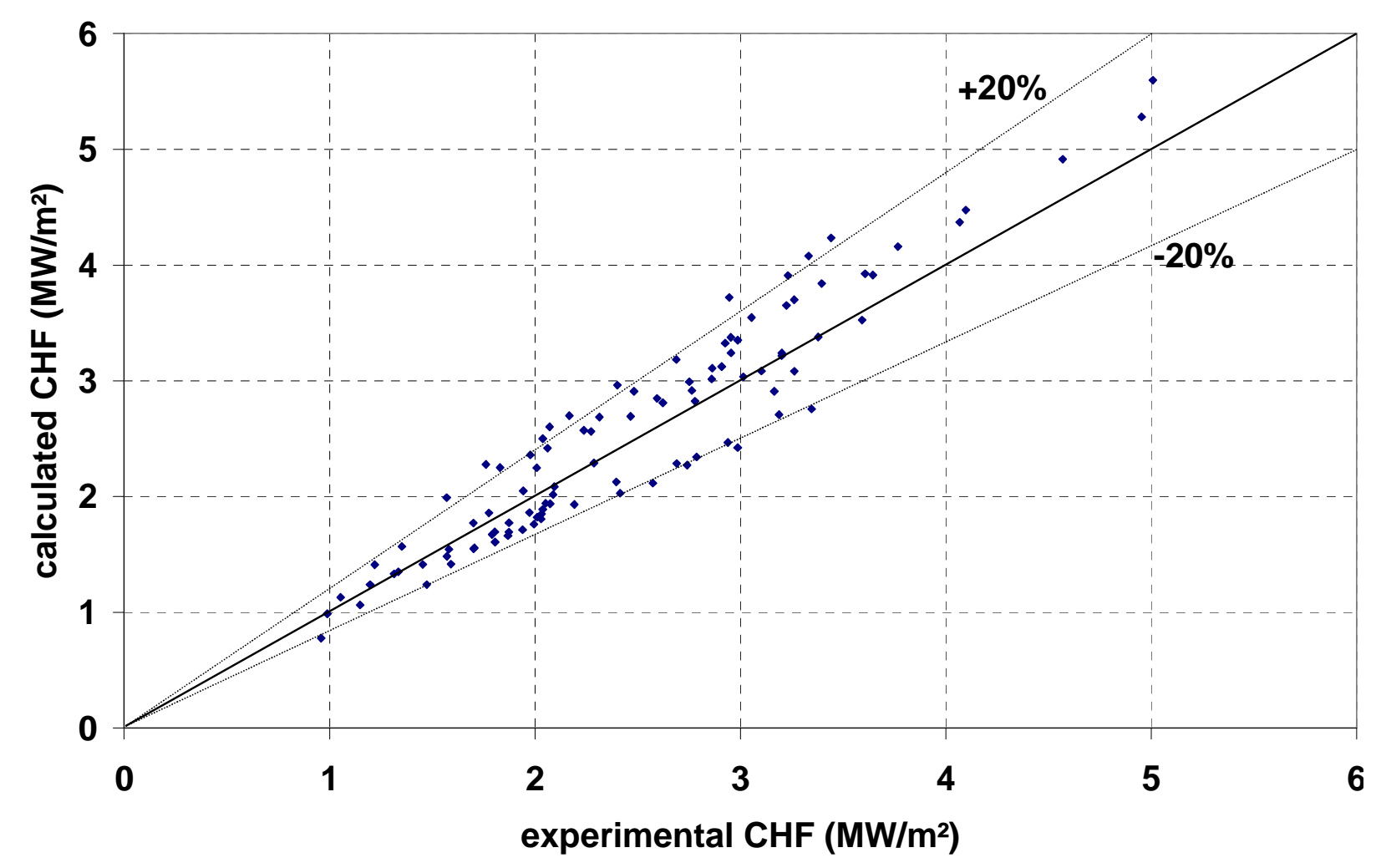

Figure 10a : Comparison between data and calculated CHF using (22), upstream

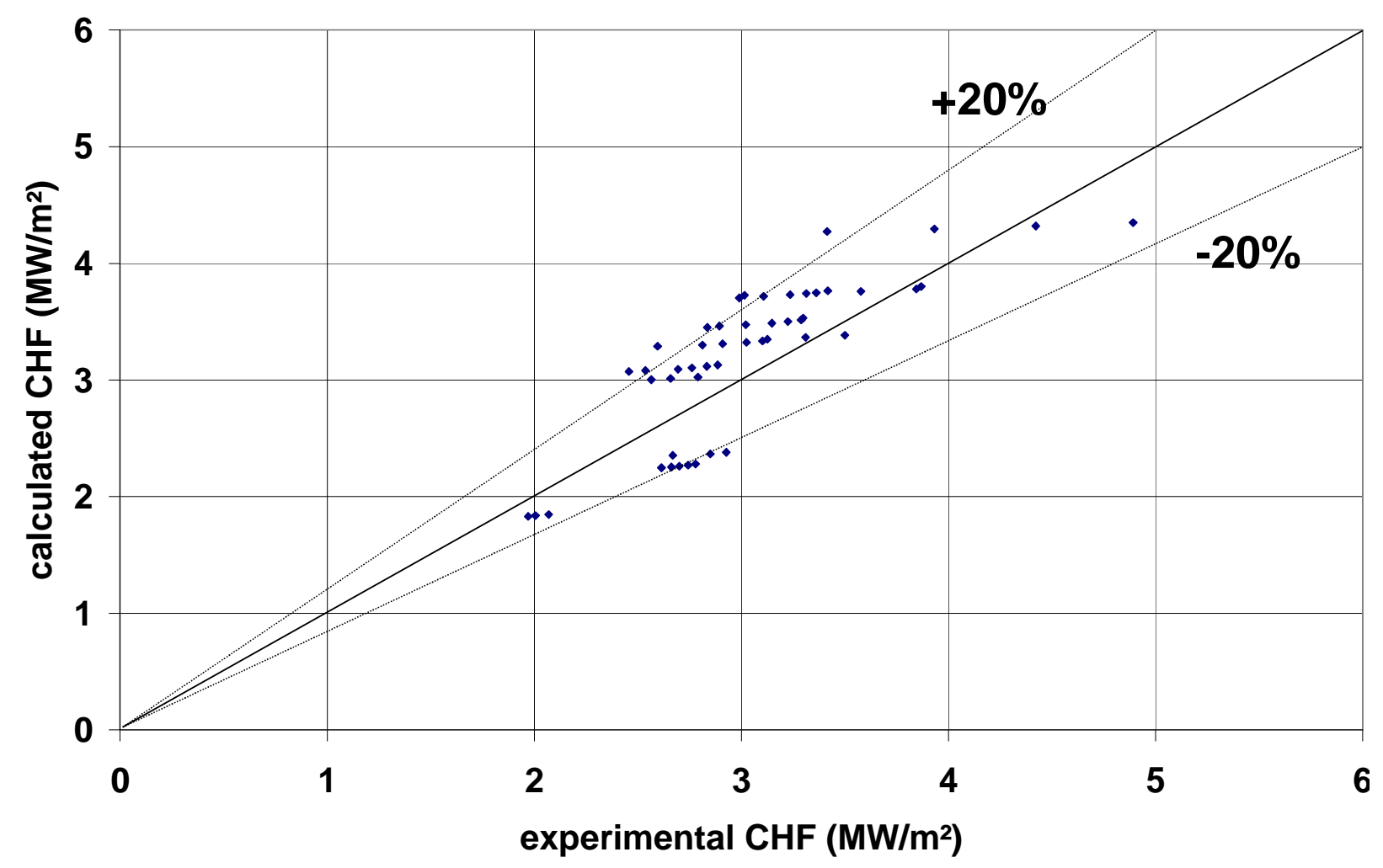

Figure 10b :Comparison between data and calculated CHF using (22), downstream 


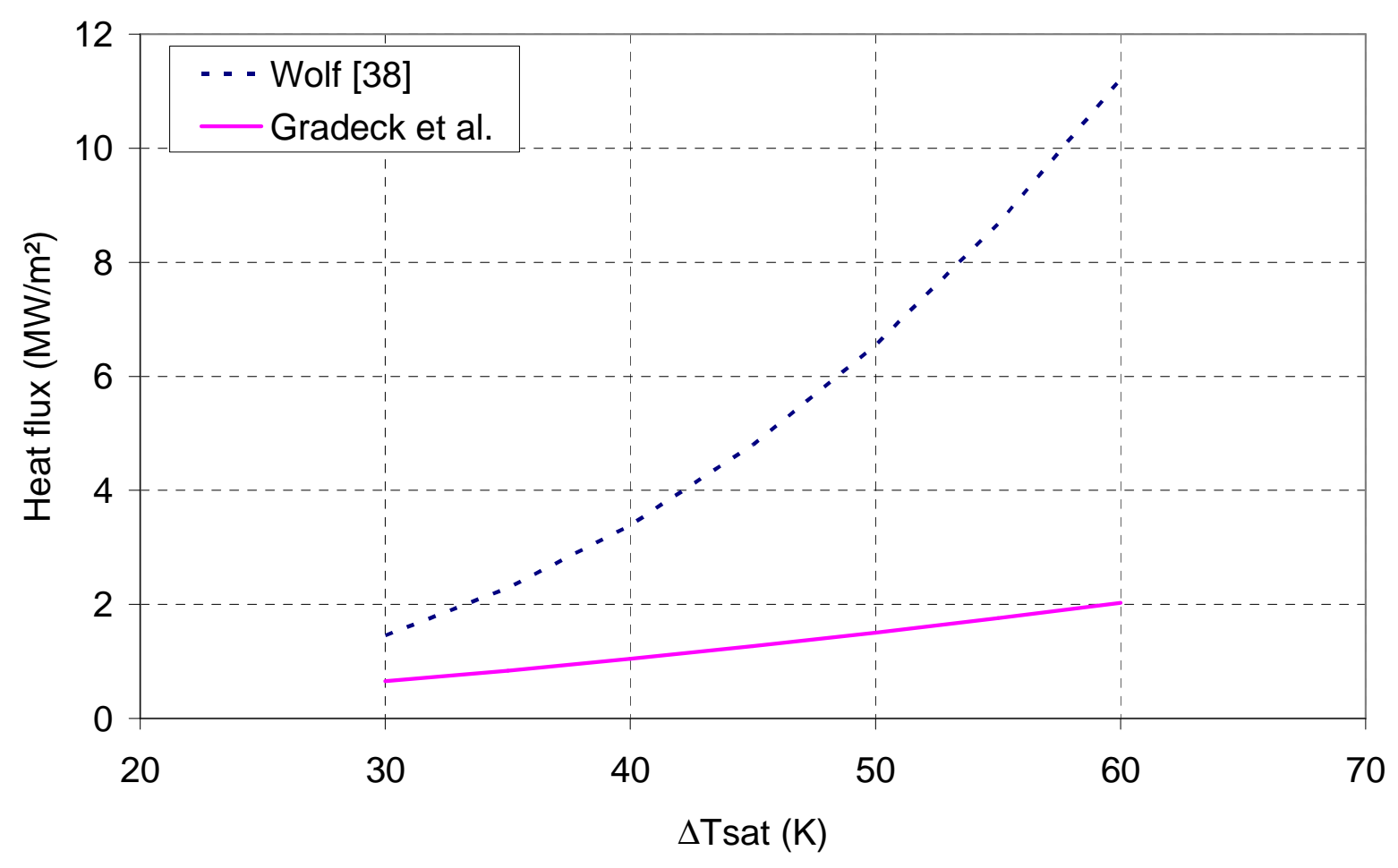

Figure 11a : comparison of the correlations (12) and (17) for nucleate boiling

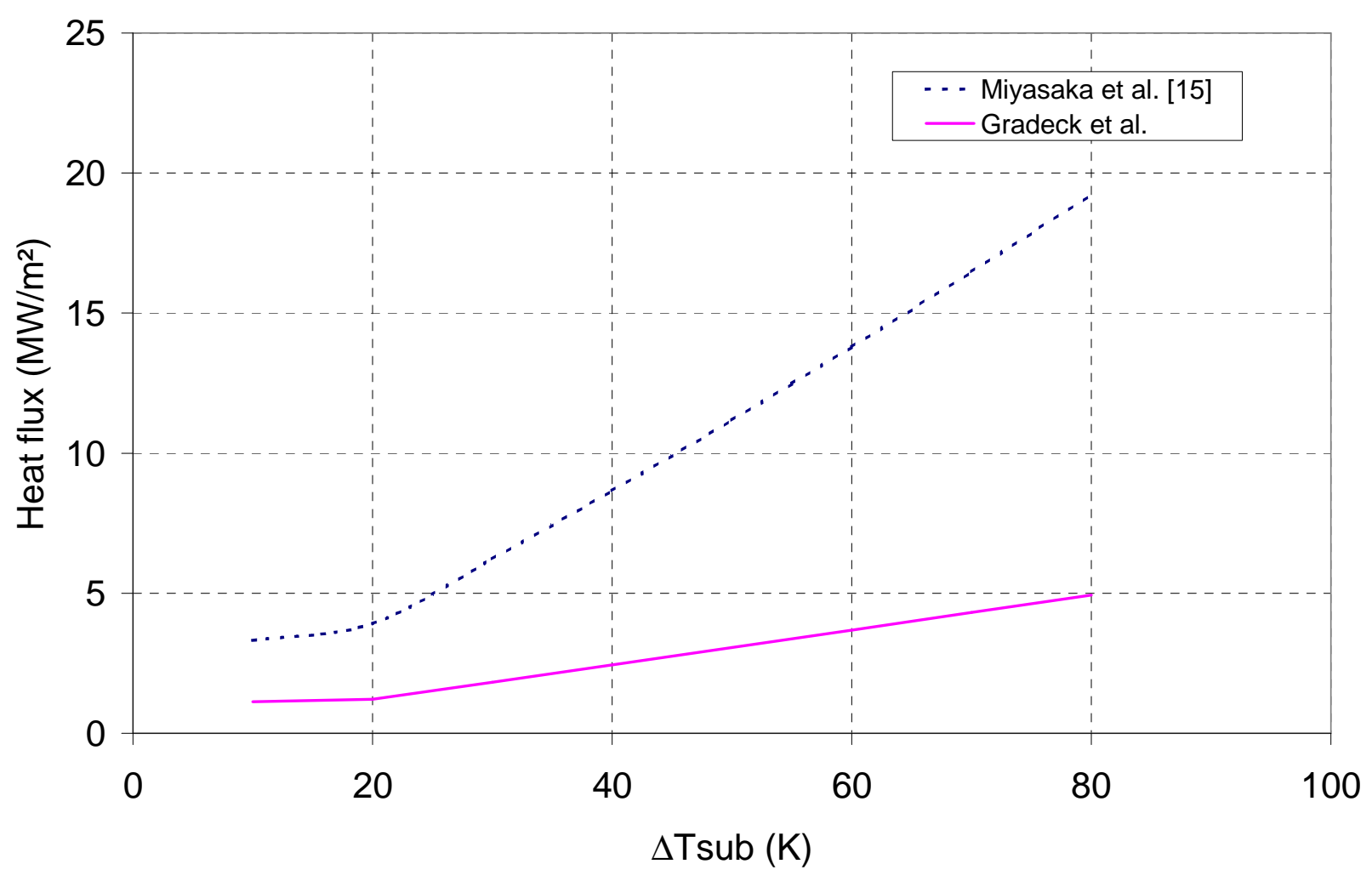

Figure 11b : comparison of the correlations (12b) and (22) for CHF, $x^{*}=0, r^{*}=0$ 